\title{
Regulation of Bcl-xL-ATP Synthase Interaction by Mitochondrial Cyclin B1-Cyclin-Dependent Kinase-1 Determines Neuronal Survival
}

\author{
Miguel Veas-Pérez de Tudela, ${ }^{1,2 *}$ María Delgado-Esteban, ${ }^{1,2 *}$ Carolina Maestre, ${ }^{1}$ Verónica Bobo-Jiménez, ${ }^{1,2}$ \\ Daniel Jiménez-Blasco, ${ }^{1,2}$ Rebeca Vecino, ${ }^{1,2}$ Juan P. Bolaños, ${ }^{1,2}$ and ${ }^{\circledR}$ Angeles Almeida ${ }^{1,2}$ \\ ${ }^{1}$ Institute of Biomedical Research of Salamanca, University Hospital of Salamanca, and ${ }^{2}$ Institute of Functional Biology and Genomics, University of \\ Salamanca-Spanish National Research Council, E-37007 Salamanca, Spain
}

\begin{abstract}
The survival of postmitotic neurons needs continuous degradation of cyclin B1, a mitotic protein accumulated aberrantly in the damaged brain areas of Alzheimer's disease and stroked patients. Degradation of cyclin B1 takes place in the proteasome after ubiquitylation by the anaphase-promoting complex/cyclosome (APC/C)- cadherin 1 (Cdh1), an E3 ubiquitin ligase that is highly active in neurons. However, during excitotoxic damage-a hallmark of neurological disorders-APC/C-Cdh1 is inactivated, causing cyclin B1 stabilization and neuronal death through an unknown mechanism. Here, we show that an excitotoxic stimulus in rat cortical neurons in primary culture promotes cyclin B1 accumulation in the mitochondria, in which it binds to, and activates, cyclin-dependent kinase-1 (Cdk1). The cyclin $\mathrm{B} 1-\mathrm{Cdk} 1$ complex in the mitochondria phosphorylates the anti-apoptotic protein B-cell lymphoma extra-large (Bcl-xL), leading to its dissociation from the $\beta$ subunit of $\mathrm{F}_{1} \mathrm{~F}_{\mathrm{o}}-\mathrm{ATP}$ synthase. The subsequent inhibition of ATP synthase activity causes complex I oxidative damage, mitochondrial inner membrane depolarization, and apoptotic neuronal death. These results unveil a previously unrecognized role for mitochondrial cyclin B1 in the oxidative damage associated with neurological disorders.
\end{abstract}

Key words: Bcl-xL; cyclin B1; excitotoxicity; F1Fo-ATP synthase; mitochondria; neurodegeneration

\section{Introduction}

An increasing body of evidence indicates that the progressive neuronal death associated with neurodegenerative diseases is a consequence of a failed attempt of postmitotic neurons to aberrantly reenter the cell cycle (Herrup, 2013). Thus, in patients suffering from Alzheimer's disease (Vincent et al., 1997; Yang et al., 2003) and stroke (Love, 2003), as well as in experimental models of cerebral ischemia (Erdö et al., 2004; Wen et al., 2004; Rashidian et al., 2007), the affected brain areas aberrantly accumulate cyclin B1. This is compatible with the notion that cyclin B1 may be involved in the neuronal death associated with those pathologies. In healthy neurons, cyclin B1 is degraded persistently after ubiquitylation by the E3 ubiquitin ligase anaphase-

\footnotetext{
Received Nov. 16, 2014; revised May 6, 2015; accepted May 8, 2015.

Author contributions: J.P.B. and A.A. designed research; M.V.-P.d.T., M.D.-E., C.M., V.B.-J., D.J.-B., R.V., and A.A. performed research; M.V.-P.d.T., M.D.-E., J.P.B., and A.A. analyzed data; A.A. wrote the paper.

This work was funded by Instituto de Salud Carlos III Grants PI12/00685 and RD12/0014/0007 (A.A.P.), RD12/ 0043/0021 (J.P.B.), F110/00492 (M.V.-P.d.T.), and (P14/00010 (M.D.-E.), Ministerio de Economia y Competitividad Grant SAF2013-41177-R (J.P.B.), SP3-People-MC-ITN programme of the European Commission Grant 608381 (J.P.B.), and the European Regional Development Fund. The technical assistances of Monica Carabias and Monica Resch are acknowledged.

*M.V.-P.d.T. and M.D.-E. contributed equally to this work.

The authors declare no competing financial interests.

Correspondence should be addressed to Angeles Almeida, Institute of Biomedical Research of Salamanca, University Hospital of Salamanca, Calle Zacarías González, 2, E-37007 Salamanca, Spain. E-mail: aaparra@usal.es.

C. Maestre's present address: Cell Division and Cancer Group, Spanish National Cancer Research Centre, E-28029 Madrid, Spain.

DOI:10.1523/JNEUROSCI.4712-14.2015

Copyright $\odot 2015$ the authors $\quad 0270-6474 / 15 / 359287-15 \$ 15.00 / 0$
}

promoting complex/cyclosome (APC/C)-cadherin 1 (Cdh1; Almeida et al., 2005). However, during excitotoxic damage-a hallmark of neurological disorders (Bolaños et al., 2009; Wang and Qin, 2010)—APC/C-Cdh1 is inactivated, causing aberrant stabilization of cyclin B1 (Maestre et al., 2008), which mediates neuronal death (Almeida et al., 2005; Maestre et al., 2008) through a yet elusive molecular mechanism.

Excitotoxicity is one of the most common phenomena that underlie the pathophysiology of neurological disorders (Wang and Qin, 2010) and involves overactivation of glutamatergic receptors triggering massive $\mathrm{Ca}^{2+}$ entry into the postsynaptic neuron. After an excitotoxic insult, mitochondria are thus overloaded of $\mathrm{Ca}^{2+}$, resulting in inner membrane potential $\left(\Delta \psi_{\mathrm{m}}\right)$ disruption, which precedes neuronal apoptotic death (Bolaños et al., 2009). Accordingly, keeping $\Delta \psi_{\mathrm{m}}$ intact represents an interesting therapeutic strategy against neurodegeneration (Smith et al., 2008). However, besides mitochondrial $\mathrm{Ca}^{2+}$ (Duchen, 2012), there are other yet unknown factor(s) responsible for the $\Delta \psi_{\mathrm{m}}$ loss and neuronal death. Here, we show that, during an excitotoxic stimulus, cyclin B1 is accumulated in the mitochondria, accounting for the $\Delta \psi_{\mathrm{m}}$ loss and neuronal death. Furthermore, we found that this effect occurred through cyclin B1-mediated activation of cyclin-dependent kinase-1 (Cdk1), which phosphorylated B-cell lymphoma extra-large (Bcl-xL), resulting in its dissociation from the $\beta$ subunit of $\mathrm{F}_{1} \mathrm{~F}_{\mathrm{o}}-\mathrm{ATP}$ synthase. The subsequent inhibition in ATP synthase activity caused increased mitochondrial superoxide anion $\left(\mathrm{O}_{2}^{\cdot-}\right)$ that damaged 
complex I, leading to the $\Delta \psi_{\mathrm{m}}$ loss and bioenergetic crisis responsible for apoptotic neuronal death.

\section{Materials and Methods}

Ethical statement regarding the use of animals. All animals (pregnant Wistar female rats) used in this work were obtained from the Animal Experimentation Service of the University of Salamanca, in accordance with Spanish legislation (RD 1201/2005) under license from the Spanish government. Protocols were approved by the Bioethics Committee of the University of Salamanca.

Cell cultures. Primary cultures of rat cortical neurons were prepared from fetal Wistar rats (of either sex) of $16 \mathrm{~d}$ of gestation (Maestre et al., 2008), seeded at $2.5 \times 10^{5}$ cells $/ \mathrm{cm}^{2}$ in different-sized plastic plates coated with poly-D-lysine $(15 \mu \mathrm{g} / \mathrm{ml})$ and incubated in DMEM (SigmaAldrich) supplemented with $10 \%$ fetal calf serum (FCS; Roche Diagnostics). Cells were incubated at $37^{\circ} \mathrm{C}$ in a humidified $5 \% \mathrm{CO}_{2}$-containing atmosphere. At $48 \mathrm{~h}$ after plating, the medium was replaced with DMEM supplemented with 5\% horse serum (Sigma-Aldrich), 20 mM D-glucose, and, on day 4 , cytosine arabinoside $(10 \mu \mathrm{M})$ to prevent non-neuronal proliferation. Cells were used for the experiments on day 6-7 in vitro. Human embryonic kidney-293T (HEK293T) cells were maintained in DMEM supplemented with $10 \%$ (v/v) FCS. Twenty-four hours before the experiment, cells were reseeded at $1.8 \times 10^{5} \mathrm{cells} / \mathrm{cm}^{2}$ in plates coated previously with poly-D-lysine $(15 \mu \mathrm{g} / \mathrm{ml})$.

Plasmid constructions and site-directed mutagenesis. The following plasmid constructions were used: (1) pIRES2-EGFP (Invitrogen), either empty [control; expressing green fluorescent protein (GFP)] or containing the full-length cDNA of human Cyclin B1 (Cyclin B1; expressing both cyclin B1 and GFP; Maestre et al., 2008); (2) pcDNA3-GFP (expressing GFP) or pcDNA3-cyclin B1-GFP, encoding human cyclin B1 fused to GFP (from J. Pines, Gurdon Institute, University of Cambridge, Cambridge, UK; Almeida et al., 2005); (3) pSuper-neo.gfp (Oligoengine), including the small hairpin sequences for luciferase (control; 5'-CTGACGCGGAATACTTCGA-3') or cyclin B1 (shCyclin B1; 5' GATGGAGCTGATCCAAACC-3'; nucleotides 478-496, GenBank accession number AY338491; Almeida et al., 2005; Maestre et al., 2008); (4) pMitoDsRed2 plasmid vector (MitoRed; Clontech), expressing red fluorescent protein in mitocondria; and (5) p8-Bcl-xL (from F. Pimentel, Cancer Research Institute, University of Salamanca, Spanish National Research Council, Salamanca, Spain) was subjected to site-directed mutagenesis on Ser42, which was replaced by Ala or Asp residues to obtain the phosphodefective [Bcl-xL(A); to block Cdk1 phosphorylation] and phosphomimetic [Bcl-xL(D)] forms of Bcl-xL (GenBank accession number NM_138578.1), respectively, using the QuikChange XL kit (Stratagene), followed by DpnI digestion. The forward and reverse oligonucleotides designed were as follows, respectively: 5'-TGGCACCTGGCAGACGCCCCCGCGGTGAATGGA- $3^{\prime}$ and $5^{\prime}$-TCCATTCACCGCGGGGGCGTCTGCCAGGTGCCA-3' for Ser42Ala; and 5'-TGGCACCTGGCAGACGACCCCGCGGTGAATGGA-3' and $5^{\prime}$-TCCATTCACCGCGGGGTCGTCTGCCAGGTGCCA-3' for Ser42Asp.

Small interfering RNA. Specific depletion of Cdk5 was achieved by using small ( $21 \mathrm{bp}$ ) interfering double-stranded ribonucleotides (siRNA) designed specifically to target the coding sequence of the rat Cdk5 mRNA (Maestre et al., 2008). We used the following siRNA (only the forward strand shown): 5'-AAGCCGUACCCGAUGUAUC-3' (nucleotides 859-877, GenBank accession number NM_080885). An siRNA against luciferase (5' -CUGACGCGGAAUACUUCGAUU-3') was used as control siRNA (siControl; Maestre et al., 2008). Annealed siRNAs were purchased from Dharmacon (Abgene, Thermo Fisher Scientific).

Cell transfections and treatments. All transfections with plasmid constructions were performed using Lipofectamine 2000 (Invitrogen; Maestre et al., 2008), following the instructions of the manufacturer. After transfections, cells were incubated further for $4-24 \mathrm{~h}$ until the experiments and cell collection were performed. Transfections of neurons with siRNAs were performed using Lipofectamine RNAiMAX (Invitrogen) following the instructions of the manufacturer and used after $72 \mathrm{~h}$.

To promote an excitotoxic insult, neurons were incubated with 100 $\mu \mathrm{M}$ glutamate plus $10 \mu \mathrm{M}$ glycine in HBSS (in mM: $134.2 \mathrm{NaCl}, 5.26 \mathrm{KCl}$, $0.43 \mathrm{KH}_{2} \mathrm{PO}_{4}, 4.09 \mathrm{NaHCO}_{3}, 0.33 \mathrm{Na}_{2} \mathrm{HPO}_{4}, 5.44$ glucose, 20 HEPES, and $4 \mathrm{CaCl}_{2}, \mathrm{pH} 7.4$ ) for $5 \mathrm{~min}$ and incubated further in culture medium for the indicated time period (Almeida and Bolaños, 2001). When indicated, incubations were performed in the presence of $100 \mathrm{ng} / \mathrm{ml}$ actinomycin D (ActD; Sigma), $1 \mu \mathrm{g} / \mathrm{ml}$ cycloheximide (CHX; Sigma), $10 \mu \mathrm{M}$ ProTAME (Boston Biochem, R\&D Systems), and $1 \mathrm{~mm}$ glutathione ethyl ester (GSH-EE; Sigma) or with $10 \mu \mathrm{M}$ roscovitine (Rosc; Sigma).

Subcellular fractionation. Cells were washed with cold PBS containing $1 \mathrm{mM} \mathrm{MgCl}_{2}$, harvested with cytosolic buffer (10 mM HEPES, $1.5 \mathrm{~mm}$ $\mathrm{MgCl}_{2}, 10 \mathrm{~mm} \mathrm{KCl}, 1 \mathrm{~mm}$ EDTA, 0.1\% NP-40, v/v, $1.5 \mathrm{~m}$ sucrose, and protease and phosphatase inhibitors mixture, $\mathrm{pH}$ 7.9), triturated with a micropipette to promote cell lysis, left on ice for $30 \mathrm{~min}$, and vortexed for $10 \mathrm{~s}$. After checking cell lysis under a light microscope, extracts were centrifuged at $830 \times g$ for $10 \mathrm{~min}$. Lysis of the nuclei was performed by resuspending the nuclear pellet in nuclear buffer (50 mM HEPES, $1.5 \mathrm{~mm}$ $\mathrm{MgCl}_{2}, 10 \mathrm{~mm} \mathrm{KCl} \mathrm{mm}, 0.5 \mathrm{~mm} \mathrm{NaCl}, 1 \mathrm{~mm}$ EDTA, 1\% NP-40, v/v, and protease and phosphatase inhibitor mixture, $\mathrm{pH} 7.9$ ), triturated with a micropipette, left on ice for $2 \mathrm{~h}$, vortexed $(10 \mathrm{~s})$, boiled $(5 \mathrm{~min})$, and sonicated $(5 \mathrm{~min})$. The supernatant (mitochondrial and cytosolic fractions) was then centrifuged at $17,000 \times \mathrm{g}$ for $12 \mathrm{~min}\left(4^{\circ} \mathrm{C}\right)$, and the cytosolic fraction (supernatant) was lysed in $2 \times$ RIPA buffer ( $2 \%$ sodium dodecylsulphate, 2 mм EDTA, 2 mм EGTA, and 50 mм Tris, $\mathrm{pH}$ 7.5), supplemented with phosphatase inhibitors $\left(1 \mathrm{mM} \mathrm{Na}_{3} \mathrm{VO}_{4}\right.$ and 50 $\mathrm{mM} \mathrm{NaF}$ ) and protease inhibitors [100 $\mu \mathrm{M}$ phenylmethylsulfonyl fluoride (PMSF), $50 \mu \mathrm{g} / \mathrm{ml}$ anti-papain, $50 \mu \mathrm{g} / \mathrm{ml}$ pepstatin, $50 \mu \mathrm{g} / \mathrm{ml}$ amastatin, $50 \mu \mathrm{g} / \mathrm{ml}$ leupeptin, $50 \mu \mathrm{g} / \mathrm{ml}$ bestatin, and $50 \mu \mathrm{g} / \mathrm{ml}$ soybean trypsin inhibitor], and boiled for $5 \mathrm{~min}$ (Maestre et al., 2008). The mitochondrial fraction (pellet) was resuspended in isolation medium (in mM: $320 \mathrm{su}-$ crose, 1 potassium EDTA, and 10 Tris- $\mathrm{HCl}, \mathrm{pH} 7.4$ ) and was homogenized in a tight-fitting glass-Teflon homogenizer (20 strokes; Almeida and Medina, 1998). Mitochondrial fraction was either lysed with $2 \times$ RIPA buffer for protein analysis by immunoblotting or used for the identification of intramitochondrial localization of cyclin B1, as described below.

Mitochondrial fraction was incubated in buffer (in mm: 1 EDTA and 10 MOPS-KOH, pH 7.2) containing 320 or 70 mm sucrose on ice for $30 \mathrm{~min}$ and was centrifuged at $16,000 \times g$ at $4^{\circ} \mathrm{C}$ for $10 \mathrm{~min}$. Pellets were resuspended in RIPA buffer, and all fractions were analyzed by immunoblotting.

The protease protection assay (Wang et al., 2014 1) was performed by incubating mitochondrial fraction in buffer (in mM: 1 EDTA, 10 MOPS-KOH, and 320 sucrose, $\mathrm{pH}$ 7.2) on ice for $30 \mathrm{~min}$ with or without 25 or $50 \mu \mathrm{g} / \mathrm{ml}$ trypsin. Proteolysis was stopped by addition of $1 \mathrm{~mm}$ PMSF, and samples were centrifuged $16,000 \times g$ at $4^{\circ} \mathrm{C}$ for 10 min. Pellet were resuspended in RIPA buffer, and proteins were analyzed by immunoblotting.

Western blot. Cells were lysed in 2\% sodium dodecylsulphate, $2 \mathrm{~mm}$ EDTA, 2 mM EGTA, and 50 mm Tris, pH 7.5, supplemented with phosphatase inhibitors $\left(1 \mathrm{mM} \mathrm{Na}_{3} \mathrm{VO}_{4}, 50 \mathrm{~mm} \mathrm{NaF}\right.$ ) and protease inhibitors (100 $\mu \mathrm{M}$ phenylmethylsulfonyl fluoride, $50 \mu \mathrm{g} / \mathrm{ml}$ anti-papain, $50 \mu \mathrm{g} / \mathrm{ml}$ pepstatin, $50 \mu \mathrm{g} / \mathrm{ml}$ amastatin, $50 \mu \mathrm{g} / \mathrm{ml}$ leupeptin, $50 \mu \mathrm{g} / \mathrm{ml}$ bestatin, and $50 \mu \mathrm{g} / \mathrm{ml}$ soybean trypsin inhibitor), stored on ice for $30 \mathrm{~min}$, and boiled for $10 \mathrm{~min}$. Aliquots of cell extracts were subjected to SDS polyacrylamide gel (MiniProtean; Bio-Rad) and blotted with primary antibodies at dilutions ranging from 1:200 to $1: 1000$ overnight at $4^{\circ} \mathrm{C}$. Antibodies used were anti-cyclin B1 (BD Biosciences Pharmingen), antiCdk1 (Santa Cruz Biotechnology) anti-voltage-dependent anion channel (VDAC; Merck Millipore), anti-proliferating cell nuclear antigen (BD Biosciences Pharmingen), anti-GAPDH (Ambion), anti-Bcl-xL (BD Biosciences), anti-phosphoserine (Zymed, Invitrogen), anti- $\beta$-ATPase (Abcam), anti-Hsp60 (Abcam), anti-translocase of the outer mitochondrial membrane 20 (TOM20; Abcam), and anti-Ndusf1 [NADH dehydrogenase (ubiquinone) $\mathrm{Fe}-\mathrm{S}$ protein $1,75 \mathrm{kDa}$ (NADH-coenzyme Q reductase); Santa Cruz Biotechnology]. After incubation with horseradish peroxidase-conjugated goat anti-rabbit IgG (Santa Cruz Biotechnology) or goat anti-mouse IgG (1:10,000 dilution; Santa Cruz Biotechnology), membranes were incubated immediately with the enhanced chemiluminescence kit SuperSignal West Dura (Pierce, Thermo Fisher Scientific) for 5 min or Immobilon Western Chemiluminiscent HRP Substrate (Merck Millipore) for $1 \mathrm{~min}$, before exposure to Kodak 
XAR-5 film for 1-5 min, and the autoradiograms were scanned. Biologically independent replicates (three to four different independent cell cultures) were always performed, and a representative Western blot is shown. The protein abundances were measured by densitometry of the bands on the films using NIH ImageJ version $1.48 \mathrm{u} 4$ software and were normalized against the corresponding loading control.

$R T$-PCR. Total RNA was purified from neurons using a commercially available kit (Sigma). Cyclin B1 and GAPDH mRNA expression was analyzed by 3\% agarose electrophoresis after RT-PCR using the following forward and reverse oligonucleotides, respectively: 5'-CAACTGGAGGAAGAGCAGTCA3' and 5'-CATCTGAACCTGTATTAGCCA-3' for Cyclin B1; and 5' - GGGTGTGAACCACGAGAAAT-3' and 5' - GACTGTGGTCATGAGCCCTT-3' for GAPDH. RT was performed at $48^{\circ} \mathrm{C}$ for $50 \mathrm{~min}$, and PCR conditions were 10 min at $95^{\circ} \mathrm{C}, 35$ cycles of $30 \mathrm{~s}$ at $95^{\circ} \mathrm{C}, 30 \mathrm{~s}$ at $52^{\circ} \mathrm{C}$, and $1 \mathrm{~min}$ at $72^{\circ} \mathrm{C}$. Final extension was performed for $10 \mathrm{~min}$ at $72^{\circ} \mathrm{C}$. In no case was a band detected by PCR without RT.

Cdk1 kinase assay. Cells were lysed in ice-cold buffer containing $50 \mathrm{~mm}$ Tris, pH 7.5, 150 mм NaCl, 2 mm EDTA, and 1\% NP-40, supplemented with the phosphatase and protease inhibitors cited above. After clearing debris by centrifugation, extracts ( $200 \mu \mathrm{g}$ protein) were incubated with anti-Cdk1 $(2 \mu \mathrm{g})$ for $4 \mathrm{~h}$ at $4^{\circ} \mathrm{C}$, followed by the addition of $30 \mu \mathrm{l}$ of protein A-Sepharose (GE Healthcare) for $2 \mathrm{~h}$ at $4^{\circ} \mathrm{C}$. Immunoprecipitates were washed four times in lysis buffer and resuspended in kinase buffer (in mM: 50 HEPES, pH 7.5, $10 \mathrm{MgCl}_{2}, 1$ EDTA, and 0.1 dithiothreitol) containing $20 \mu \mathrm{M}$ ATP, $2 \mu \mathrm{Ci}$ of $\left[\gamma^{-}{ }^{32} \mathrm{P}\right] \mathrm{ATP}$, and histone $\mathrm{H} 1(1$ $\mathrm{mg} / \mathrm{ml}$; Sigma-Aldrich). Samples were subjected to SDS-PAGE (12\%), and transferred proteins were visualized by autoradiography or blotted with anti-Cdk1.

Coimmunoprecipitation assay. Cells were lysed in ice-cold buffer containing $50 \mathrm{~mm}$ Tris- $\mathrm{HCl}, \mathrm{pH}$ 7.5, $150 \mathrm{~mm} \mathrm{NaCl}, 2 \mathrm{~mm}$ EDTA, and 1\% NP-40, supplemented with the phosphatase and protease inhibitors cited in Western blot analysis. Cell extracts were clarified by centrifugation, and supernatants ( $500 \mu \mathrm{g}$ of protein) were incubated with $2 \mu \mathrm{g}$ of anti$\mathrm{Bcl}-\mathrm{xL}$ for $4 \mathrm{~h}$ at $4^{\circ} \mathrm{C}$, followed by the addition of $30 \mu \mathrm{l}$ of protein A-Sepharose (GE Healthcare) for $2 \mathrm{~h}$ at $4^{\circ} \mathrm{C}$. Immunoprecipitates were washed extensively with lysis buffer and detected by Western blot analysis (Gomez-Sanchez et al., 2011).

Isolation of mitochondria. Mitochondrial fractions were isolated as described by Almeida and Medina (1998), which provides a rapid method for isolation of intact functional mitochondria from cultured cells. In brief, cells were washed twice with cold PBS and collected in isolation medium (in mM: 320 sucrose, 1 potassium EDTA, and 10 Tris- $\mathrm{HCl}, \mathrm{pH}$ 7.4), centrifuged at $600 \times g$ for $5 \mathrm{~min}\left(4^{\circ} \mathrm{C}\right)$, and resuspended in isolation medium. Cells were homogenized in a tight-fitting glass-Teflon homogenizer (20 strokes), and the nuclei and lysed membranes were removed by centrifugation at $1500 \times g$ for $10 \mathrm{~min}\left(4^{\circ} \mathrm{C}\right)$. We then centrifuged the supernatant at $17,000 \times g$ for $11 \mathrm{~min}\left(4^{\circ} \mathrm{C}\right.$ ), and pellet (mitochondrial fraction) was suspended in isolation buffer. The supernatant contained the cytosolic fraction.

Blue native PAGE and immunoblotting for oxidized protein detection. Isolated mitochondria $(0.5 \mathrm{mg}$ of protein) were treated with $50 \mathrm{~mm}$ $\mathrm{N}$-ethylmaleimide (NEM) for $10 \mathrm{~min}$ at $37^{\circ} \mathrm{C}$, pelleted, and washed with isolation medium (in mм: 320 sucrose, 1 potassium EDTA, and 10 Tris- $\mathrm{HCl}$, $\mathrm{pH}$ 7.4). Then, mitochondria were treated with $2 \mathrm{~mm}$ dithiothreitol for 10 min and washed with isolation medium. After treating mitochondria with 25 mM iodoacetyl-LC-biotin for $10 \mathrm{~min}$ in the dark, mitochondria were incubated in ice-cold digitonin buffer [1\% (w/v) digitonin, $1 \mathrm{~m}$ 6-aminohexanoic acid, and $50 \mathrm{~mm}$ Bis-Tris $\mathrm{HCl}, \mathrm{pH} 7.0]$ for $5 \mathrm{~min}$ in ice. After centrifugation for $30 \mathrm{~min}$ at $13,000 \times \mathrm{g}$, the supernatant was collected, and $5 \%(\mathrm{v} / \mathrm{v})$ Coomassie Brilliant Blue G-250 in 1 м 6-aminohexanoic acid was added to the supernatant. Samples were resolved on a 1-mm-thick 3-12\% polyacrylamide gradient gel. Gel was dyed with a nitroblue tetrazolium test to remark the situation of complex I, and the band was excised with a razor blade and incubated for $5 \mathrm{~min}$ at room temperature in $125 \mathrm{~mm}$ Tris- $\mathrm{HCl}$, $\mathrm{pH} 7.0$, containing $1 \%$ SDS and $50 \mathrm{~mm}$ NEM before insertion over the 1.5 -mm-thick SDS-polyacrylamide gel. Stacking gel was polymerized around the excised bands, and proteins were separated by electrophoresis in a MiniProtean system (Bio-Rad). Oxidized proteins were detected after blotting onto nitrocellulose membranes with streptavidin-horse- radish peroxidase conjugate (1:1000; Thermo Fisher Scientific) to visualize biotinylated reagents. Signal detection was performed with an enhanced chemiluminescence kit (Hurd et al., 2008).

Determination of mitochondrial enzyme activities. Cells were collected by trypsinization, centrifuged, and resuspended in $300 \mu \mathrm{l}$ of $0.1 \mathrm{M}$ potassium phosphate buffer, $\mathrm{pH}$ 7.0. Samples were freeze-thawed three times to ensure cellular disruption. Enzyme activities were measured in cell lysates (80-100 $\mu \mathrm{g}$ of protein) at $30^{\circ} \mathrm{C}$ using a Kontron spectrophotometer (Uvikon XL; NorthStar Scientific). Nicotinamide adenine dinucleotide (NADH)-CoQ1 reductase (complex I) activity was measured as the rotenone-sensitive rate of NADH oxidation (at $340 \mathrm{~nm}$; Ragan et al., 1987). Cell lysates was incubated in $25 \mathrm{~mm}$ potassium phosphate, $\mathrm{pH} 7.2$, containing $0.2 \mathrm{~mm} \mathrm{NADH}, 10 \mathrm{~mm} \mathrm{MgCl}_{2}, 1 \mathrm{~mm} \mathrm{KCN}$, and $2.5 \mathrm{mg}$ of fat-free bovine serum albumin (BSA), and the reaction was initiated with $50 \mu \mathrm{M}$ ubiquinone-1. For measurement of the rotenone-insensitive $\mathrm{NADH}$ oxidation activity, the assay was also performed in the presence of $10 \mu \mathrm{M}$ rotenone.

Succinate-cytochrome $c$ reductase (complex II-III) activity was measured as the antimycin A-sensitive rate of cytochrome $c$ reduction (at 550 $\mathrm{nm}$; King, 1967). The reaction mixture contained $100 \mathrm{~mm}$ potassium phosphate, $\mathrm{pH}$ 7.4, 0.3 mm EDTA, $1 \mathrm{~mm} \mathrm{KCN}$, and $0.1 \mathrm{~mm}$ cytochrome $c$ and was initiated with $20 \mathrm{~mm}$ succinate. The assay was also performed in the presence of $20 \mu \mathrm{g} / \mathrm{ml}$ antimycin A to determine the actimycin A-insensitive complex II-III activity.

Cytochome $c$ oxidase (complex IV) was measured as the rate of cytochrome $c$ oxidation (at $550 \mathrm{~nm}$; Wharton and Tzagoloff, 1967). The test cuvette contained $10 \mathrm{~mm}$ potassium phosphate, $\mathrm{pH} 7.0$, and $50 \mu \mathrm{M}$ reduced cytochrome $c$. The reference cuvette also contained $1 \mathrm{~mm}$ $\mathrm{K}_{3} \mathrm{Fe}(\mathrm{CN})_{6}$. The reaction was initiated by adding cell lysate to the test cuvette, and the first-order velocity constant $(k)$ was calculated.

The ATPase activity was measured in a linked enzyme system as the oligomycin-sensitive rate of NADH oxidation (at $340 \mathrm{~nm}$ ), using the method of Soper and Pedersen (1979). The oxidation of NADH to $\mathrm{NAD}^{+}$results from a coupled reaction catalyzed by pyruvate kinase and lactate dehydrogenase in the presence of phosphoenolpyruvate, dependent on ADP production by the ATPase in the presence of ATP. The reaction mixture contained $50 \mathrm{~mm}$ Tris- $\mathrm{HCl}, \mathrm{pH} 8.0,5 \mathrm{~mm}$ phosphoenolpyruvate, 2 mм KCN, 0.3 mm NADH, 100 mm HCl, $6 \mathrm{~mm} \mathrm{MgCl}_{2}, 10$ $\mu \mathrm{M}$ rotenone, $25 \mathrm{U} / \mathrm{ml}$ lactate dehydrogenase, $25 \mathrm{U} / \mathrm{ml}$ pyruvate kinase, and $6 \mathrm{~mm}$ ATP. The rate inhibited by the addition of $5 \mu \mathrm{g} / \mathrm{ml}$ olygomycin was taken to be the ATPase activity.

Citrate synthase activity was measured as in the study by Shepherd and Garland (1966) (at $412 \mathrm{~nm}$ ). Cell lysates were incubated in $100 \mathrm{~mm}$ Tris-HCl, pH 8.0, $0.1 \mathrm{~mm}$ acetyl-CoA, $0.2 \mathrm{~mm}$ 5,5'-dithiobis(2nitrobenzoic acid), $0.1 \%(\mathrm{v} / \mathrm{v})$ Triton X-100, and $200 \mu \mathrm{M}$ oxaloacetate.

All enzyme activities were expressed as nanomoles per minute per milligram of protein, except for cytochrome $c$ oxidase, which was expressed as the first-order rate constant $(k)$ per minute per milligram of protein.

Oxygen consumption assay. Cells were removed from the flasks by mild trypsinization. The rate of oxygen consumption was measured in $10^{6}$ cells suspended in HBSS (containing $5.5 \mathrm{~mm}$ glucose) at $30^{\circ} \mathrm{C}$, using a Clark-type dissolved oxygen electrode (Digital model 20; Rank Brothers). Results are expressed as nanomoles of $\mathrm{O}_{2}$ consumed per minute per $10^{6}$ cells (Almeida et al., 2001)

Immunocytochemistry. Neurons grown on glass coverslips were fixed with $4 \%$ (v/v, in PBS) paraformaldehyde for $30 \mathrm{~min}$ and immunostained with mouse anti-Cyclin B1 (1:100) and rabbit anti-Bcl-xL (1:100; BD Biosciences) antibodies (Gomez-Sanchez et al., 2011). Immunolabeling was detected using anti-mouse IgG-Cy3 (1:500) or anti-rabbit IgG-Cy5 (1:500; Jackson ImmunoResearch). Coverslips were washed, mounted in SlowFade light antifade reagent (Invitrogen) on glass slides, and examined using a scanning laser confocal microscope (TSC SL; Leica) with three lasers [multiline argon $(458,488 \mathrm{~nm})$, green helium-neon $(543$ $\mathrm{nm})$, and red helium-neon $(633 \mathrm{~nm})]$ and equipped with $40 \times, 63 \times(1.4$ numerical aperture) HCX PL Apo oil-immersion objectives for highresolution imaging.

Flow cytometric detection of apoptotic cell death. Neurons were detached carefully from the plates using $1 \mathrm{~mm}$ EDTA (tetrasodium salt) in PBS, $\mathrm{pH}$ 
7.4, and were stained with annexin $\mathrm{V}$-adenomatous polyposis coli (APC) and 7-aminoactinomycin $\mathrm{D}$ (7-AAD) in binding buffer (in mм: 100 HEPES, $140 \mathrm{NaCl}$, and $2.5 \mathrm{CaCl}_{2}$ ) to determine quantitatively the percentage of apoptotic neurons by flow cytometry. Cells were stained with annexin V-APC and 7-AAD in binding buffer (in mM: 100 HEPES, 140 $\mathrm{NaCl}$, and $2.5 \mathrm{CaCl}_{2}$ ), according to the instructions of the manufacturer, and $3 \times 10^{5}$ cells were analyzed, in four replicates per condition, on a FACScalibur flow cytometer $(15 \mathrm{~mW}$ argon ion laser tuned at $488 \mathrm{~nm}$; CellQuest software; BD Biosciences). Transfected (identified by GFP fluorescence) cell populations were analyzed, and the annexin V-APCstained cells that were 7-AAD-negative were considered to be apoptotic (Gomez-Sanchez et al., 2011).

Flow cytometric detection of active caspase-3. Active caspase-3 was detected in the GFP-expressing $\left(\mathrm{GFP}^{+}\right)$neurons using the ApoActive3 kit (Bachem). After detaching cells with 1 mM EDTA (tetrasodium salt) and centrifuging, cell pellets were fixed during $20 \mathrm{~min}$, resuspended in PBS plus $2 \% \mathrm{BSA}$, and incubated for $1 \mathrm{~h}$ with $1 \times$ rabbit anti-caspase 3 . Cells were then incubated with 1:500 anti-rabbit Cy3 (Jackson ImmunoResearch) for $1 \mathrm{~h}$. Between each step, cells were washed with either PBS (until labeling of samples) or PBS plus 1\% BSA and resuspended in PBS plus 1\% BSA before analysis by flow cytometry (tuned at $488 \mathrm{~nm}$; CellQuest software; BD Biosciences).

Flow cytometric detection of $\Delta \psi_{m}$ and mitochondrial superoxide generation. $\Delta \psi_{\mathrm{m}}$ was assessed using the MitoProbe DilC1(5) Assay Kit for Flow Cytometry (Invitrogen), and stained cells were analyzed on the FL1 and FL4 channels of a FACScalibur flow cytometer (15 mW argon ion laser tuned at $488 \mathrm{~nm}$; CellQuest software; BD Biosciences). $\Delta \psi_{\mathrm{m}}$ values were expressed as percentages, using carbonyl cyanide 4-(trifluoromethoxy) phenylhydrazone $(10 \mu \mathrm{M})$ to define the $0 \% \Delta \psi_{\mathrm{m}}$ values. Mitochondrial superoxide production was assessed using the fluorescent MitoSox probe (Invitrogen) by flow cytometry, as described previously (QuintanaCabrera et al., 2012).

Protein determinations. Protein concentrations were determined in the cell suspensions, lysates, or in parallel cell culture incubations after solubilization with $0.1 \mathrm{M} \mathrm{NaOH}$. Protein concentrations were determined as described previously (Lowry et al., 1951), using BSA as standard.

Statistical analysis. All measurements in cell culture were performed, at least, in triplicate, and the results are expressed as the mean \pm SEM values from at least three different culture preparations. For the comparisons between two groups of values, the statistical analysis of the results was performed by the Student's $t$ test. For multiple values comparisons, we used one-way ANOVA, followed by Bonferroni's test. The statistical analysis was performed using the SPSS 16.0 software for Macintosh. In all cases, $p<0.05$ was considered significant.

\section{Results}

Cyclin B1-Cdk1 activity mediates neuronal apoptotic death via the mitochondrial pathway on an excitotoxic stimulus

To investigate the molecular mechanism responsible for cyclin B1-mediated neurodegeneration, neurons were incubated with $100 \mu \mathrm{M}$ glutamate for $5 \mathrm{~min}$, followed by harvesting at different time points, a previously validated excitotoxic stimulus known to cause cyclin B1 stabilization (Maestre et al., 2008). As shown in Figure $1 A$, glutamate triggered a time-dependent accumulation of endogenous cyclin B1 in whole-cell extracts, confirming our previous findings (Maestre et al., 2008).

Cyclin B1 mRNA was unaltered (Fig. 1B), and its protein accumulation was not prevented by the transcription inhibitor ActD and the protein synthesis inhibitor CHX (Fig. 1C), indicating that glutamate induced cyclin B1 protein stabilization by a posttranslational mechanism. We reported that APC/C-Cdh1 activity destabilizes cyclin $\mathrm{B} 1$ protein as an essential survival mechanism for neurons (Almeida et al., 2005). Moreover, excitotoxic stimulus inactivates APC/C-Cdh1, causing aberrant cyclin B1 stabilization that leads to apoptotic neuronal death (Maestre et al., 2008). Here, we show that the APC/C inhibitor ProTAME mimicked glutamate-induced cyclin B1 accumulation
(Fig. 1D). In accordance with the finding that the inactivation of APC/C-Cdh1 during excitotoxicity requires Cdk5 (Maestre et al., 2008), this protein was knocked down by RNA interference using a previously validated siRNA against Cdk5 (siCdk5; Maestre et al., 2008), which resulted in the abolishment of glutamateinduced cyclin B1 accumulation (Fig. 1E). Altogether, these results confirm our previous findings (Maestre et al., 2008) that an excitotoxic stimulus activates Cdk5, which inhibits APC/C, leading to aberrant cyclin B1 accumulation.

During the excitotoxic insult, the increase in cyclin B1 protein paralleled that of Cdk1 activity, as assessed by its ability to phosphorylate histone $\mathrm{H} 1$ (Fig. $1 F$ ), suggesting functional activation of the cyclin B1-Cdk1 complex. Furthermore, such Cdk1 activation was abolished by siRNA-mediated knockdown of Cdk5 (Fig. $1 F)$, confirming the involvement of Cdk5 in this process. To assess whether the cyclin B1-Cdk1 complex was responsible for neuronal death after the excitotoxic stimulus, we next knocked down cyclin B1 using a previously validated shRNA ( shCyclin B1; Almeida et al., 2005) or inhibited Cdk(s) with Rosc. As shown in Figure $1 G$, both treatments mostly attenuated the timedependent neuronal apoptotic death triggered by glutamate. Conversely, ectopic expression of cyclin B1 triggered a timedependent increase in apoptotic neuronal death (Fig. 2A) and loss of cyclin B1-containing $\left(\mathrm{GFP}^{+}\right)$neurons (Fig. $2 B$ ) that reached the statistical significance after $18 \mathrm{~h}$ of transfection. Axonal disruption, characteristic of apoptotic death, was also observed by epifluorescence after $24 \mathrm{~h}$ of the ectopic expression of a cyclin B1 (Fig. 2B). Moreover, active caspase- 3 was increased in cyclin B1-expressing neurons as assessed by flow cytometry (Fig. $2 C)$, confirming apoptotic death. Cyclin B1-mediated apoptotic death was abolished by the caspase inhibitors zVAD-fmk and zDEVD-fmk, as well as by the caspase-3-specific inhibitor zDQMD-fmk (Fig. 2D). However, inhibiting caspase-8 with zIETD-fmk or caspase-2 with zVDVAD-fmk failed to prevent cyclin B1-mediated apoptotic death (Fig. 2D), ruling out the non-mitochondrial apoptotic pathway in the process. In contrast, inhibition of mitochondrial-dependent caspase- 9 with zLEHD-fmk fully prevented cyclin B1-mediated apoptotic death (Fig. 2D). Thus, cyclin B1 induces neuronal apoptotic death via the intrinsic mitochondrial pathway through caspase-3/ caspase- 9 activation.

\section{Cyclin B1-Cdk1 accumulates in mitochondria on the excitotoxic stimulus, leading to oxidative stress and energy deficiency}

In view of the evidence for a mitochondrial involvement in cyclin B1-mediated neuronal apoptotic death, we next sought to investigate whether cyclin B1, and its catalytic partner Cdk1, occurred in this organelle. Interestingly, glutamate treatment promoted the accumulation of endogenous cyclin B1 and Cdk1 in mitochondria purified from neurons, as revealed by Western blotting (Fig. 3A). This was confirmed in HEK293T cells transfected with the full-length cDNA encoding cyclin B1 (Fig. $3 B$ ).

To further corroborate the occurrence of cyclin B1 in mitochondria, neurons were cotransfected with MitoRedwhich delivers the red fluorescent protein specifically into mitochondria - and cyclin B1-GFP (or GFP alone as control) cDNA constructs. Confocal images showed that MitoRed fluorescence colocalized with that of GFP in neurons transfected with the cyclin B1-GFP fusion cDNA (cyclin B1 neurons) but not with those transfected with GFP alone (control neurons; Fig. $3 C$ ). Thus, the accumulation of cyclin $\mathrm{B} 1$ protein during either glutamate treatment or exogenous cyclin B1 expression occurs primarily in mi- 


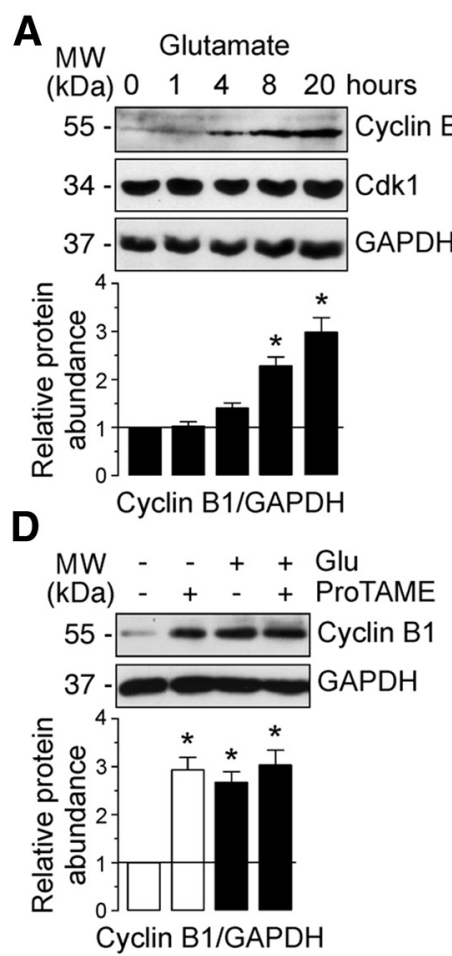

G

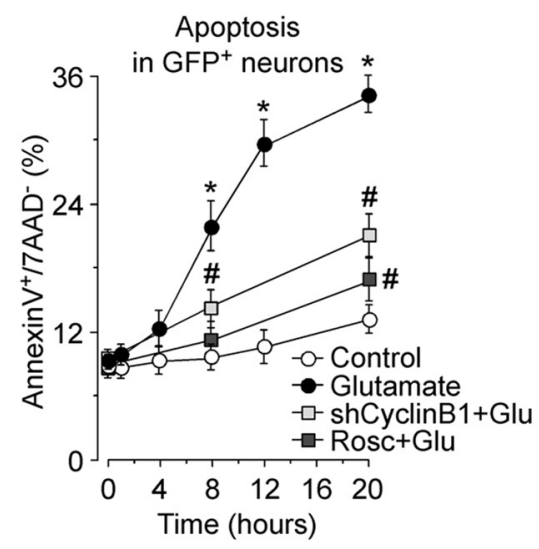

B

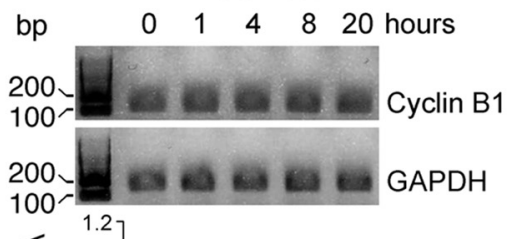

E
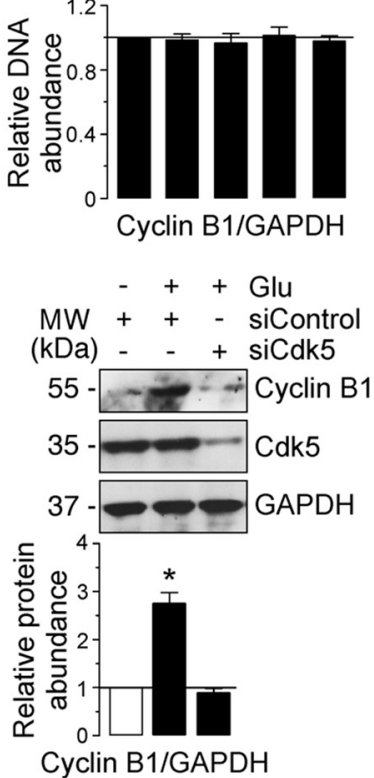

C

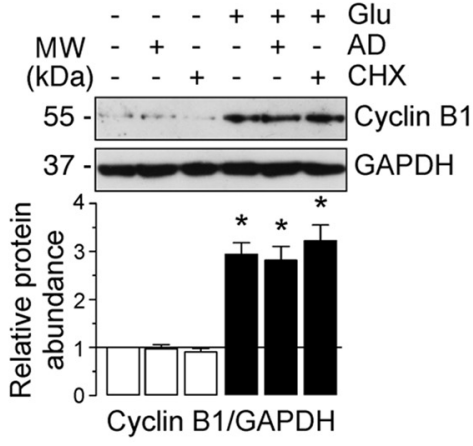

Glutamate

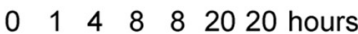

$\mathrm{MW}+++-+-+$ siControl

(kDa) - - -++ - siCdk5

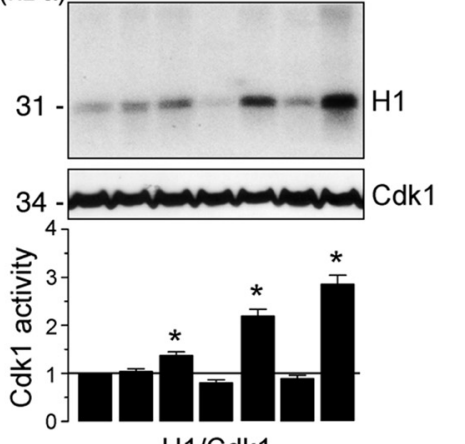

$\mathrm{H} 1 / \mathrm{Cdk} 1$
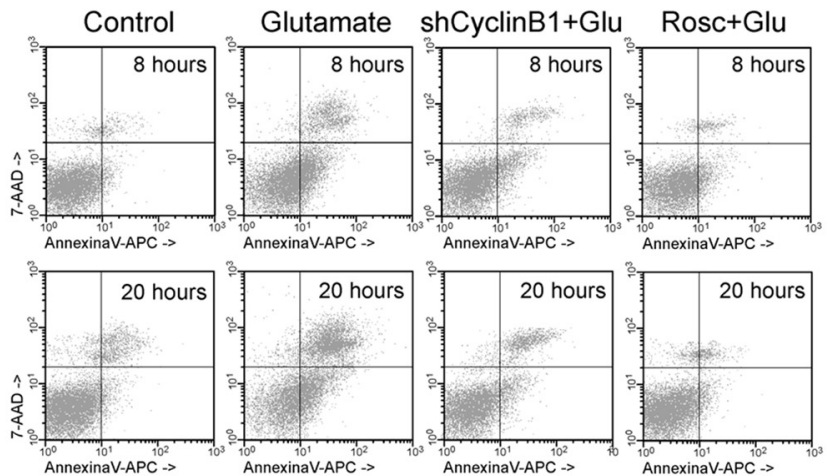

Figure 1. Cyclin B1-Cdk1 activity mediates neuronal apoptotic death on an excitotoxic stimulus. Rat cortical neurons were treated with glutamate (100 $\mu \mathrm{m}, 5 \mathrm{~min})$ and were further incubated in culture medium for 1-20 h.A, Western blots of neuronal extracts were probed sequentially with antibodies to cyclin B1 and Cdk1, followed by GAPDH as loading control. B, CyclinB1 and GAPDH mRNA expression was analyzed by $3 \%$ agarose electrophoresis after RT-PCR. GAPDH is a housekeeping gene and used as loading control in PCR. One representative gel is shown of three. Shown is the relative cyclin B1 $\mathrm{mRNA}$ levels, as normalized with GAPDH, averaged from three independent neuronal cultures $(n=3)$. After glutamate stimulation (100 $\mu \mathrm{M}, 5 \mathrm{~min})$, neurons were incubated in culture medium containing the transcriptional inhibitor ActD $(100 \mathrm{ng} / \mathrm{ml})$, the protein synthesis inhibitor CHX $(1 \mu \mathrm{g} / \mathrm{ml})$, or the APC/C inhibitor ProTAME (10 $\mu \mathrm{m})$ for $20 \mathrm{~h}$. C, Treatment with ActD or CHX did not prevent glutamate-induced cyclin B1 accumulation in neurons. D, ProTAME promoted neuronal cyclin B1 stabilization. $\boldsymbol{E}$, Neurons on day 4 in vitro were transfected with an siRNA against luciferase (siControl; $100 \mathrm{~nm}$ ) or with siRNA against Cdk5 (siCdk5; $100 \mathrm{~nm}$ ) for 3 d. Knockdown of Cdk5 (siCdk5-treated neurons) prevented cyclin B1 accumulation in glutamate-treated neurons. In $A, C, D$, and $E$, a representative Western blotisshown of three. Bargraphs represent the relative cyclin B1 protein abundance, as normalized with GAPDH, averaged from at least three independent neuronal cultures. In all cases, the represented values are means \pm SEM ( $n=3-4$ independent neuronal cultures). ${ }^{*} p<0.05$ versus untreated ( - Glu) neurons. $\boldsymbol{F}$, Glutamate triggered a time-dependent stimulation of Cdk1 activity, as assessed by the ability of the protein extracts to phosphorylate, in vitro, histone H1. Transfection with siCdk5 abrogated glutamate-caused Cdk1 activation. Each bar represents the mean \pm SEM of three independent neuronal cultures. ${ }^{*} p<0.05$ versus siControl 0 h. G, Neurons on day 4 in vitro were transfected with an shRNA against luciferase (Control) or with an shRNA against cyclin B1 (shCyclin B1) for $2 \mathrm{~d}$. Then, neurons were incubated (or not in the Control condition) with glutamate (100 $\mu \mathrm{m}, 5 \mathrm{~min}$; Glutamate condition) after incubation with culture medium for the indicated time points. When indicated, Rosc (10 $\mu \mathrm{M})$ was added to the culture medium. Both shCyclin B1 and Rosc abrogated neuronal apoptotic death caused by glutamate but did not modify apoptosis in control (untreated) neurons (20 h:shCyclin B1, 13.52 $\pm 0.89 \%$; Rosc, $12.77 \pm 0.79 \%$ ), as assessed by annexin $\mathrm{V}^{+} / 7-\mathrm{AAD}^{-}$quantification by flow cytometry. Representative flow cytometric dot plots are shown of four independent experiments. Data are the mean \pm SEM from four independent neuronal cultures $(n=4) .{ }^{*} p<0.05$ versus control; ${ }^{\#} p<0.05$ versus glutamate. AD, Actinomycin D; MW, molecular weight.

tochondria. Because glutamate-mediated excitotoxicity is known to increase mitochondrial superoxide $\left(\mathrm{O}_{2}^{--}\right)$production and inner membrane depolarization, we next investigated the possible involvement of mitochondrial cyclin B1 in these phenomena. As shown in Figure 3D, mitochondrial $\mathrm{O}_{2}^{--}$time dependently increased from $4 \mathrm{~h}$ after the excitotoxic stimulus, an effect that was mostly attenuated but not abolished, by knocking down cyclin B1 with shCyclin B1, or by inhibiting Cdk1 with Rosc. Moreover, 
A

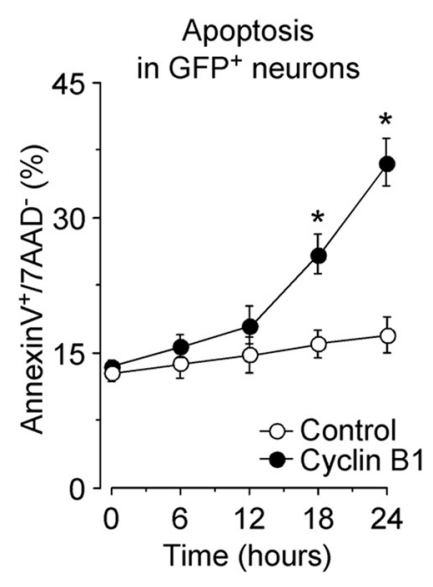

C
B
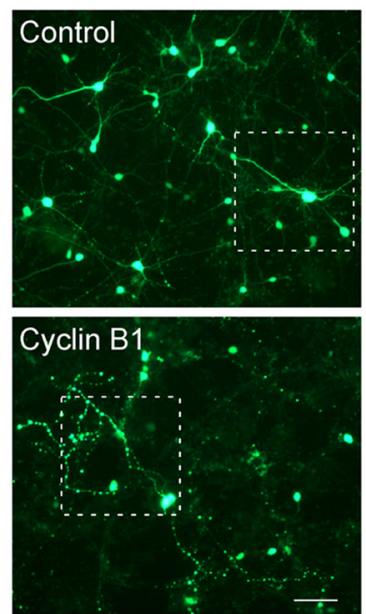

Neurons

(24 hours)
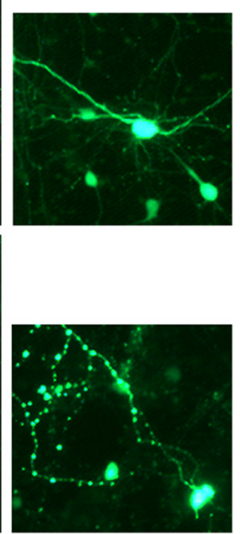

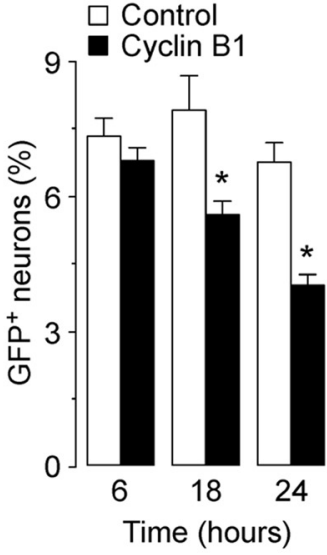

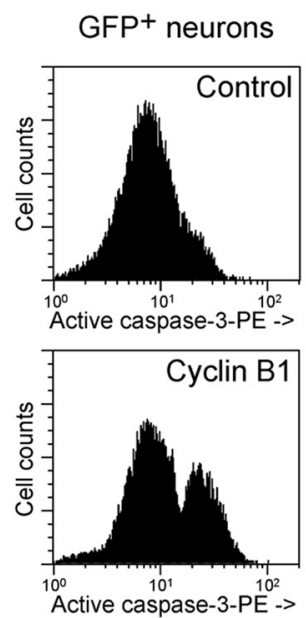

Active caspase-3
in $\mathrm{GFP}^{+}$neurons

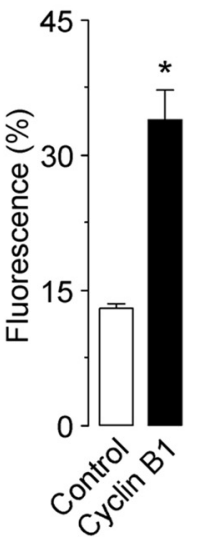

D
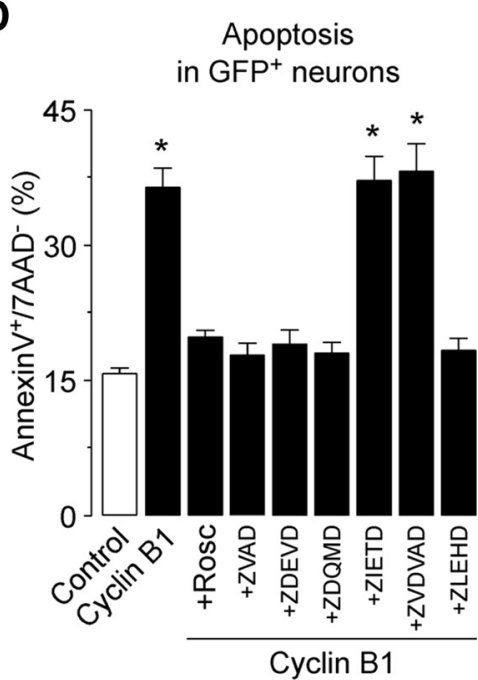

Figure 2. Cyclin B1 induces neuronal apoptotic death via the intrinsic mitochondrial pathway activation. $A$, Rat cortical neurons were transfected with $0.8 \mu \mathrm{g} / 10^{6}$ cells plRES2-EGFP, either empty (Control; expressing GFP) or containing the full-length CDNA of human cyclin B1 (Cyclin B1; expressing both cyclin B1 and GFP) for 6-24 h. cyclin B1 expression time dependently induced neuronal apoptotic death, as assessed by annexin $\mathrm{V}^{+} / 7-\mathrm{AAD}^{-}$quantification by flow cytometry. ${ }^{*} p<0.05$ versus control. $\boldsymbol{B}$, Epifluorescence microphotographs revealed the typical axonal disruption of apoptosis in cyclin B1-transfected neurons ( $24 \mathrm{~h}$ ). Scale bar, $50 \mu \mathrm{m}$. Transfection rate (percentage of GFP ${ }^{+}$neurons) was determined by flow cytometry. ${ }^{*} p<0.05$ versus control. $C$, Cyclin B1 induced caspase 3 cleavage and activation by $24 \mathrm{~h}$ after transfection of neurons, as showed by quantitative analyses of GFP ${ }^{+}$(transfected) neurons by flow cytometry. ${ }^{*}<<0.05$ versus control.D, Rosc $(10 \mu \mathrm{M})$ or caspase inhibitors (ZVAD-fmk and zDEVD-fmk; $100 \mu \mathrm{M}$ ) prevented cyclin B1-mediated neuronal death at 24h of transfection. Inhibition of caspases-8 (zIETD-fmk; $100 \mu \mathrm{M})$ or caspase-2 (zVDVAD-fmk, $100 \mu \mathrm{m}$ ) was ineffective. Caspase-3 (zDQMD-fmk; $100 \mu \mathrm{m}$ ) or caspase-9 inhibition (zLEHD-fmk; $50 \mu \mathrm{m}$ ) abrogated cyclin B1-mediated neuronal death. ${ }^{*} p<0.05$ versus control. In all cases, data are the mean \pm SEM of four independent neuronal cultures $(n=4)$.

glutamate time dependently decreased $\Delta \psi_{\mathrm{m}}$, which was prevented partially by shCyclin $\mathrm{B} 1$ or Rosc (Fig. $3 E$ ), mirroring the effects on mitochondrial $\mathrm{O}_{2}^{--}$(Fig. 3D). Interestingly, incubation of neurons with the free radical scavenger GSH-EE nearly abolished glutamate-induced $\Delta \psi_{\mathrm{m}}$ collapse (Fig. 3E), suggesting that increased $\mathrm{O}_{2}^{--}$preceded $\Delta \psi_{\mathrm{m}}$ loss. Likewise, the ectopic expression of cyclin B1 mimicked glutamate treatment, because neurons displayed a time-dependent increase in $\mathrm{O}_{2}^{--}$(Fig. $3 \mathrm{~F}$ ) and $\Delta \psi_{\mathrm{m}}$ loss (Fig. $3 G$ ). Furthermore, these effects were rescued completely by either Rosc (Fig. 3F) or GSH-EE (Fig. 3G). Thus, our time course study shows that $\Delta \psi_{\mathrm{m}}$ loss precedes apoptotic death on the excitotoxic stimulus, indicating that mitochondrial dysfunction is a cause, not a consequence, of the neuronal apoptotic process, thus confirming the importance for $\Delta \psi_{\mathrm{m}}$ maintenance in neuronal survival (White and Reynolds, 1996; Almeida and Bolaños, 2001). Because $\Delta \psi_{\mathrm{m}}$ loss on excitotoxic damage is often associated with energy depletion, we determined the concentration of neuronal ATP, which was decreased (Fig. $3 H$ ); this effect was prevented partially by Rosc, indicating the contribution of Cdk activity in energy depletion. Thus, glutamate-mediated cyclin B1-Cdk1 activation in mitochondria induces oxidative stress, leading to mitochondrial dysfunction and energy deficiency.

\section{Cyclin B1-Cdk1 activation inhibits ATP synthase, leading to} oxidative damage to complex I

Next, we aimed to understand the molecular mechanism responsible for mitochondrial dysfunction by cyclin B1-Cdk1 activity. To do so, we first analyzed the mitochondrial respiratory chain in HEK293T cells transfected with the full-length cDNA encoding cyclin $\mathrm{B} 1$. As expected, cyclin B1 protein levels time dependently increased in the transfected cells (Fig. 4A). As shown in Figure $4 B$, 
A
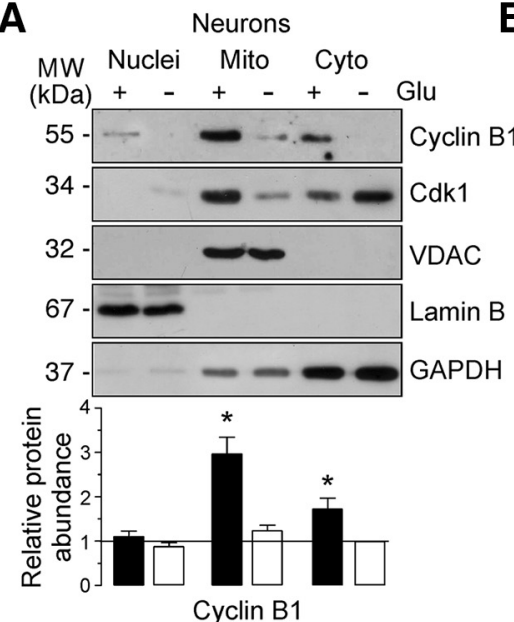

C

Control neurons

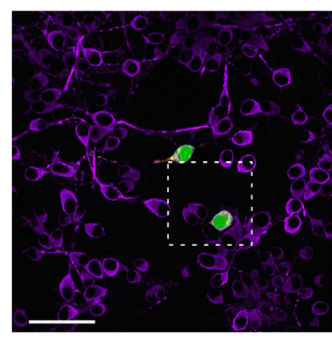

Cyclin B1 neurons
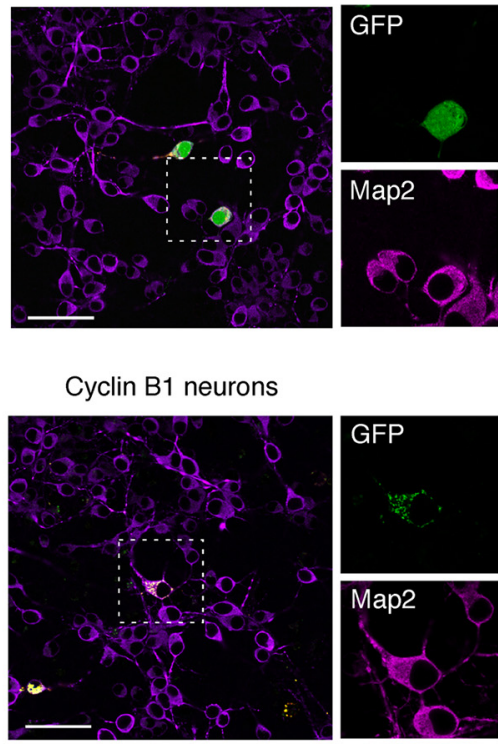

B
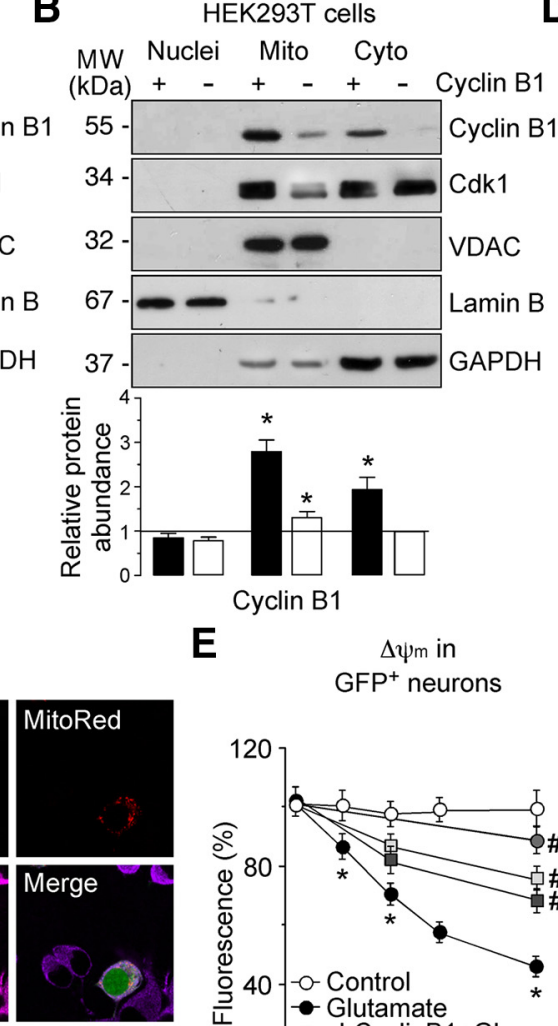

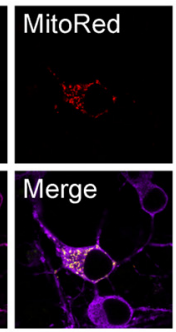

E

Cyclin B1

$\Delta \psi \mathrm{m}$ in $\mathrm{GFP}^{+}$neurons

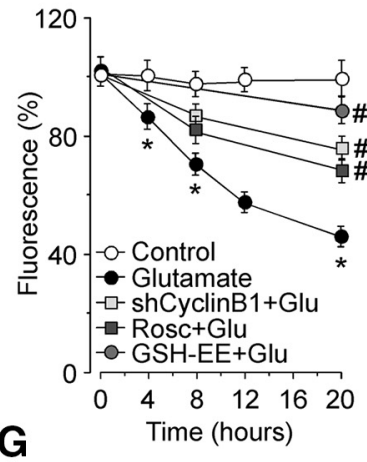

$\Delta \psi \mathrm{m}$ in $\mathrm{GFP}^{+}$neurons

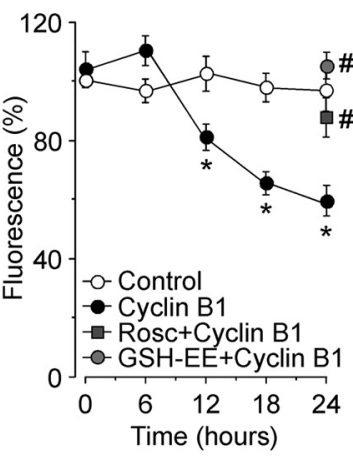

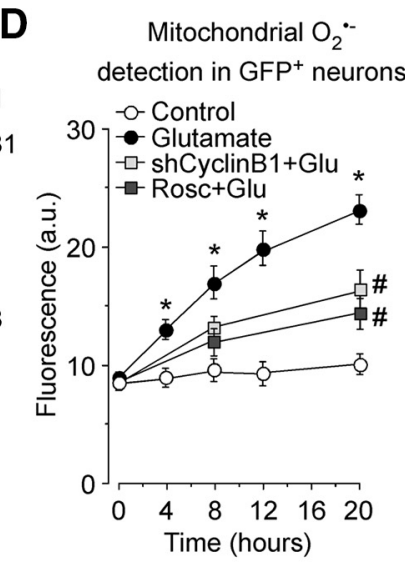

$\mathbf{F}$

Mitochondrial $\mathrm{O}_{2}{ }^{--}$ detection in $\mathrm{GFP}^{+}$neurons

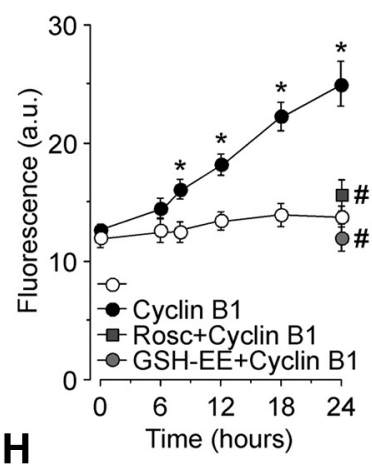

Neuronal ATP concentrations

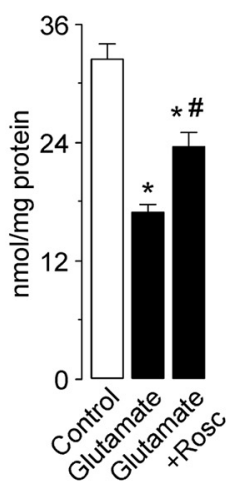

Figure 3. cyclin B1-Cdk1 accumulates in mitochondria on the excitotoxic stimulus, leading to oxidative stress and energy deficiency. $A$, Neurons were treated with $100 \mu \mathrm{m}$ glutamate for 5 min and were further incubated in culture medium for $20 \mathrm{~h}$. Western blots of nuclear (Nuclei), mitochondrial (Mito), and cytosolic (Cyto) extracts were probed sequentially with antibodies to cyclin B1 and Cdk1, followed by VDAC as mitochondrial marker, Lamin B as nuclear marker, and GAPDH as cytosolic marker. A representative Western blot is shown of three. Bar graphs represent the relative cyclin B1 protein abundance compared with the cytosolic fraction from untreated ( - Glu) cells. Each bar represents the mean \pm SEM of three independent neuronal cultures $(n=3)$. ${ }^{*} p<0.05$ versus untreated neurons. $B$, HEK293T cells were transfected with $0.8 \mu \mathrm{g} / 10^{6}$ cells pIRES2-EGFP, either empty (expressing GFP) or containing the full-length cDNA of human Cyclin B1 (expressing both cyclin B1 and GFP) for $24 \mathrm{~h}$. Western blot were performed as in $A$. Bar graphs represent the relative cyclin B1 protein abundance compared with cytosolic fraction from control ( - Cyclin B1) cells. Each bar represents the mean \pm SEM of three independent cell cultures $(n=3) .{ }^{*} p<0.05$ versus control cells. C, Neurons were cotransfected with plasmid encoding either GFP $\left(0.8 \mu \mathrm{m} / 10^{6}\right.$ cells pcDNA3-GFP; control) or cyclin B1 fused with GFP $\left(0.8 \mu \mathrm{m} / 10^{6}\right.$ cells pcDNA3-cyclin B1-GFP; cyclin B1-GFP) and the mitochondrial marker MitoRed (0.8 $\mu \mathrm{m} / 10^{6}$ cells pMitoDsRed2) for $12-14 \mathrm{~h}$. Microphotograph reveals colocalization of cyclin B1-GFP, but not GFP (control), with MitoRed in neurons. Neurons were immunostained with the neuronal marker Map2 (violet). Scale bar, $50 \mu \mathrm{m}$. $D$, Neurons on day 4 in vitro were transfected with an shRNA against luciferase (Control) or with an shRNA against cyclin B1 (shCyclin B1) for $2 \mathrm{~d}$. Then, neurons were treated with $100 \mu \mathrm{m}$ glutamate for $5 \mathrm{~min}$ and were further incubated in culture medium for $4-20 \mathrm{~h}$. When indicated, Rosc $(10 \mu \mathrm{m})$ was added to the culture medium. Glutamate time dependently induced mitochondrial $0_{2}^{--}$ generation in neurons. Both shCyclin B1 and Rosc partially abrogated glutamate-caused mitochondrial $0_{2}^{--}$generation in neurons but did not modify values in control (untreated) neurons (20 h: shCyclin B1, $10.39 \pm 0.67 \%$; Rosc, $9.33 \pm 0.54 \%$ ). ${ }^{*} p<0.05$ versus control; ${ }^{*} p<0.05$ versus glutamate. $\boldsymbol{E}$, Neurons were transfected and treated as in $\boldsymbol{D}$. Glutamate time dependently induced mitochondrial depolarization in neurons. Treatment with shCyclin B1, Rosc $(10 \mu \mathrm{M})$, and GSH-EE $(1 \mathrm{mM})$ prevented glutamate-caused $\Delta \psi_{\mathrm{m}}$ collapse in neurons. However, these treatments did not modify values in control (untreated) neurons ( $20 \mathrm{~h}$ : $\mathrm{shCyclin} \mathrm{B} 1,105.4 \pm 8.79 \%$; Rosc, $109.3 \pm 9.25 \%$; GSH-EE, $112.7 \pm 7.74) .{ }^{*} p<0.05$ versus control; ${ }^{\#} p<0.05$ versus glutamate. $F$, Neurons were transfected with $0.8 \mu \mathrm{g} / 10^{6}$ cells plRES2-EGFP, either empty (Control; expressing GFP) or containing the full-length CDNA of human cyclin B1 (Cyclin B1; expressing (Figure legend continues) 
cyclin B1 induced a time-dependent inhibition in mitochondrial complex I activity; however, complexes II-III and IV were unaffected (complex II-III: control, $2.73 \pm 0.11 \mathrm{nmol} \cdot \mathrm{min}^{-1} \cdot \mathrm{mg}^{-1}$ protein; cyclin $\mathrm{B} 1,2.60 \pm 0.13 \mathrm{nmol} \cdot \mathrm{min}^{-1} \cdot \mathrm{mg}^{-1}$ protein; complex IV: $0.33 \pm 0.03,0.27 \pm 0.03 \mathrm{k} \cdot \mathrm{min}^{-1} \cdot \mathrm{mg}^{-1}$ protein; citrate synthase: control, $135 \pm 10.3$; cyclin B1, $141 \pm 11.9)$. Interestingly, we also found that ATP synthase activity was decreased on cyclin B1 expression (Fig. 3C). Notably, inhibition of ATP synthase activity by cyclin $\mathrm{B} 1$ preceded ( $12 \mathrm{~h}$; Fig. $3 \mathrm{C}$ ) that of complex I (18 h; Fig. $3 B$ ). In view of the inhibitory effect of cyclin B1 on complex I, we sought to investigate whether the mitochondrial respiration was impaired. As shown in Figure $4 D$, the rate of $\mathrm{O}_{2}$ consumption showed a biphasic effect on cyclin B1 expression, being increased at $12 \mathrm{~h}$ and decreased at $24 \mathrm{~h}$. It is noteworthy that the increase in $\mathrm{O}_{2}$ respiration ( $12 \mathrm{~h}$; Fig. $4 \mathrm{D}$ ) occurs at a time point in which complex I was unaffected (Fig. 4B) and ATP synthase was inhibited (Fig. 4C). In view of this intriguing phenomenon, we were prompted to investigate the mechanism responsible for this effect.

Because ATP synthase inhibition is known to induce transient mitochondrial inner membrane hyperpolarization (Brand et al., 2004; Sánchez-Cenizo et al., 2010; Formentini et al., 2014), we next assessed $\Delta \psi_{\mathrm{m}}$ in cells expressing cyclin B1. As shown in Figure $4 E, \Delta \psi_{\mathrm{m}}$ increased at $12 \mathrm{~h}$, and it was followed by a decrease at $24 \mathrm{~h}$ of transfection, thus mimicking the same timedependent changes of cell $\mathrm{O}_{2}$ consumption (Fig. 4D). Thus, it is tempting to suggest that cyclin B1 primarily inhibited ATP synthase, leading to increased mitochondrial $\mathrm{O}_{2}$ consumption, $\Delta \psi_{\mathrm{m}}$ and $\mathrm{O}_{2}^{--}$, which secondarily will lead to damage to complex I. In fact, increased $\Delta \psi_{\mathrm{m}}$ enhances mitochondrial $\mathrm{O}_{2}^{--}$generation (Brand et al., 2004; Sánchez-Cenizo et al., 2010; Formentini et al., 2014), and, in neurons, cyclin B1 increased $\Delta \psi_{\mathrm{m}}$ (although it did not reach statistical significance; Fig. $3 G$ ) and mitochondrial $\mathrm{O}_{2}^{--}$ (Fig. 3F). Moreover, because mitochondrial $\mathrm{O}_{2}^{--}$causes primarily complex I oxidative damage (Bolaños et al., 2009), we then assessed whether cyclin B1-Cdk1 activity causes oxidative damage to complex. As shown in Figure 4F, cyclin B1 induced complex I oxidation, as judged by the increase in oxidized proteins detected by immunoblotting from isolated biotin-NEM-labeled mitochondrial complex I subunits. Complex I oxidation was prevented by GSH-EE (Fig. $4 F$ ) and Rosc (Fig. $4 F$ ). Furthermore, complex I inhibition caused by cyclin B1 expression in HEK293T cells was rescued by Rosc and GSH-EE (Fig. 4G). These results strongly suggest complex I oxidative damage by cyclin B1-Cdk1 activity. Moreover, ATP synthase inhibition caused by cyclin B1 expression in HEK293T cells was rescued by Rosc but not by GSH-EE, suggesting that cyclin B1-Cdk1-mediated inhibition of ATP synthase was not oxidative (Fig. $4 H$ ). Thus, we propose that

\section{$\leftarrow$}

(Figure legend continued.) both cyclin B1 and GFP) for 4-24h. When indicated, neurons were treated with Rosc $(10 \mu \mathrm{m})$ and GSH-EE (1 mm). Cyclin B1 expression time dependently induced mitochondrial $\mathrm{O}_{2}^{--}$generation in neurons, as assessed by flow cytometry. Both Rosc and GSH-EE fully prevented cyclin $\mathrm{B} 1$-mediated mitochondrial $\mathrm{O}_{2}^{-}$generation in neurons but did not modify values in control neurons ( $24 \mathrm{~h}$ : Rosc, $11.3 \pm 0.87 \%$; GSH-EE, $7.8 \pm 0.64$ ). G, Neurons were transfected and treated as in $\boldsymbol{F}$. Expression of cyclin B1 time dependently induced mitochondrial depolarization in neurons. Treatments with Rosc (10 $\mu \mathrm{m})$ and GSH-EE (1 mm) abrogated glutamate-caused $\Delta \psi_{\mathrm{m}}$ collapse in neurons. However, these treatments did not modify values in control neurons (24 h: Rosc, $102.3 \pm 8.49 \%$; GSH-EE, $109.7 \pm 9.21) .{ }^{*} p<0.05$ versus control. $\boldsymbol{H}$, Neurons were transfected and treated as in $\boldsymbol{D}$. Rosc (10 $\mu \mathrm{m})$ partially prevented ATP depletion caused by glutamate. ${ }^{*} p<0.05$ versus control; ${ }^{*} p<0.05$ versus glutamate. In $\boldsymbol{D}-\boldsymbol{H}$, data are the mean \pm SEM from four independent neuronal cultures $(n=4)$. MW, Molecular weight. the sequence of events occurring by cyclin B1-Cdk1 activation first starts by inhibiting ATP synthase, which leads to enhanced $\mathrm{O}_{2}$ consumption and $\Delta \psi_{\mathrm{m}}$, which stimulates $\mathrm{O}_{2}^{\cdot-}$. Such an increase in $\mathrm{O}_{2}^{--}$causes complex I oxidative damage, leading to the delayed impairment of cell $\mathrm{O}_{2}$ consumption.

\section{Cyclin B1-Cdk1 phosphorylates Bcl-xL, leading to its dissociation from $\beta-F_{1} F_{o}-A T P$ synthase and causing ATP} synthase and complex I inhibition on the excitotoxic stimulus We next sought to investigate the molecular mechanism whereby cyclin B1-Cdk1 inhibited ATP synthase. According to a recent study, the enzymatic activity of ATP synthase can be activated by direct interaction of its $\beta$-subunit with $\mathrm{Bcl}-\mathrm{xL}$ in neurons (Alavian et al., 2011). Conversely, in tumor cells, cyclin B1-Cdk1 phosphorylates and inactivates some members of the Bcl-2 protein family (Harley et al., 2010; Terrano et al., 2010; Sakurikar et al., 2012). Thus, we hypothesized whether the inhibition of ATP synthase activity on glutamate excitotoxicity was the consequence of a putative interference of cyclin B1-Cdk1 with the interaction between $\mathrm{Bcl}-\mathrm{xL}$ and $\beta-\mathrm{F}_{1} \mathrm{~F}_{\mathrm{o}}-\mathrm{ATP}$ synthase. In fact, confocal imaging revealed that endogenous cyclin $\mathrm{B} 1$ and $\mathrm{Bcl}-\mathrm{xL}$ colocalized in neurons after the excitotoxic stimulus (Fig. 5A). In good agreement with our Western blot analyses (Fig. $1 A$ ), cyclin B1 was absent in untreated neurons as assessed by confocal microscopy (Fig. 5A). To further confirm cyclin B1 and Bcl-xL colocalization, neurons were cotransfected with cDNA constructs encoding either GFP (control) or cyclin B1-GFP, with Bcl-xL. The results show that, whereas GFP showed a spread subcellular localization, cyclin B1-GFP colocalized with Bcl-xL (Fig. 5B). Furthermore, Bcl-xL coimmunoprecipitated with both expressed cyclin B1 (Fig. 5C) or endogenously accumulated cyclin B1 during glutamate treatment (Fig. 5D). Rosc, which binds to the ATP binding site of Cdk1 catalytic domain (De Azevedo et al., 1997), abolished such interactions (Fig. $5 C, D$ ), suggesting Bcl-xL phosphorylation by cyclin B1-Cdk1. To test this possibility directly, protein extracts obtained from either HEK293T cells expressing cyclin B1 or glutamate-treated neurons were immunoprecipitated with anti-Bcl-xL, followed by anti-phospho-Ser Western blotting. The results showed that either exogenously expressed (Fig. 6A) or endogenously accumulated (Fig. 6B) cyclin B1 phosphorylated Bcl-xL, an effect that was abrogated by Rosc (Fig. $6 A, B)$. Next, we determined whether mitochondrial cyclin B1Cdk1-mediated phosphorylation of Bcl-xL accounts for ATP synthase inhibition. Bcl-xL may occur at the outer mitochondrial membrane (Vander Heiden et al., 1997; Billen et al., 2008; Ding et al., 2014); however, other authors have described its localization at either the inner membrane or matrix, in which it would interact with the $\beta-\mathrm{F}_{1} \mathrm{~F}_{\mathrm{o}}-\mathrm{ATP}$ synthase to regulate neuronal bioenergetic efficiency of neurons (Alavian et al., 2011; Chen et al., 2011). Here, we aimed to determine the submitochondrial fraction in which cyclin $\mathrm{B} 1, \mathrm{Bcl}-\mathrm{xL}$, and $\beta-\mathrm{F}_{1} \mathrm{~F}_{\mathrm{o}}-\mathrm{ATP}$ synthase colocalized in neurons on the excitotoxic stimulus. To do this, mitoplasts were prepared by incubating mitochondria in hypotonic buffer (70 mu sucrose), and then proteins were analyzed by Western blot. In good agreement with the rupture of the outer mitochondrial membrane occurring at $70 \mathrm{~mm}$ sucrose, Tom 20, an outer mitochondrial membrane protein marker, was lost (Fig. 6C). However, cyclin $\mathrm{B} 1, \mathrm{Bcl}-\mathrm{xL}$, and $\beta-\mathrm{F}_{1} \mathrm{~F}_{\mathrm{o}}-\mathrm{ATP}$ synthase proteins were still present in these mitoplast extracts, similar to the mitochondrial matrix protein Hsp60 and the inner membrane protein Ndusf1, a complex I subunit (Fig. 6C). To further corroborate the submitochondrial localization of cyclin $\mathrm{B} 1$, a protease-protection assay was performed in mitochondria isolated from glutamate- 
A

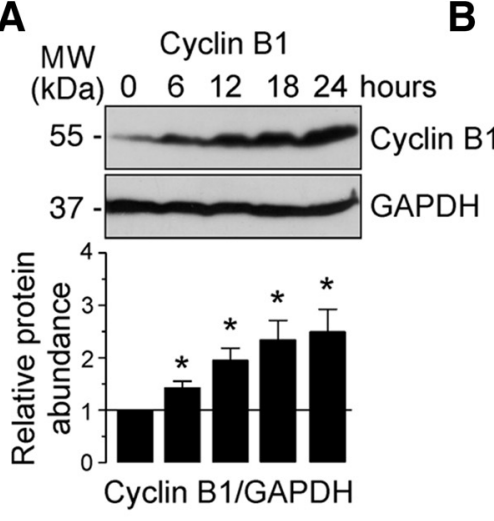

D

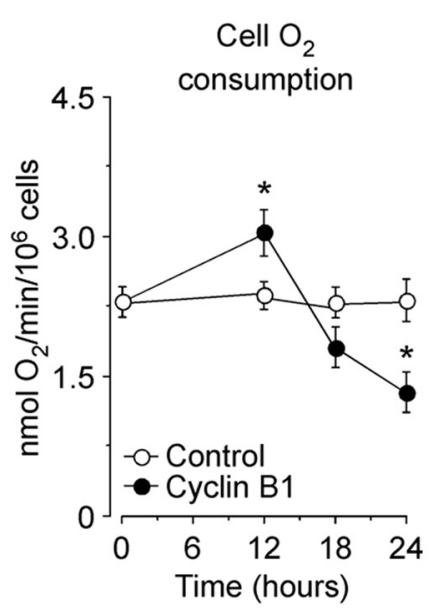

B

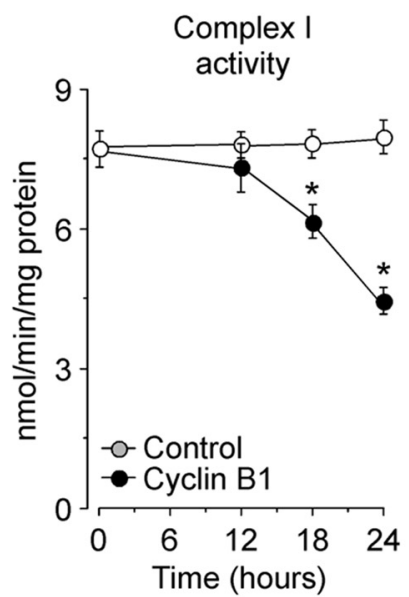

E

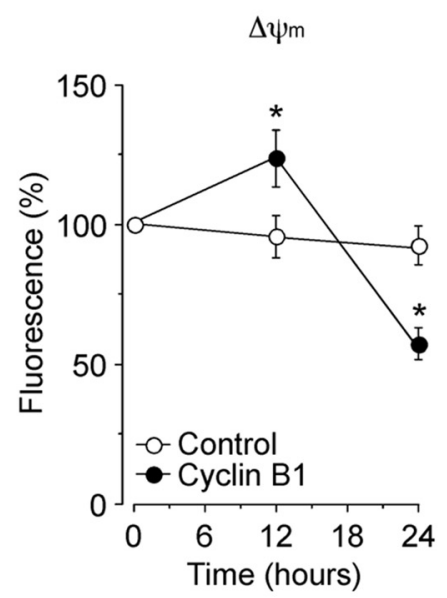

C
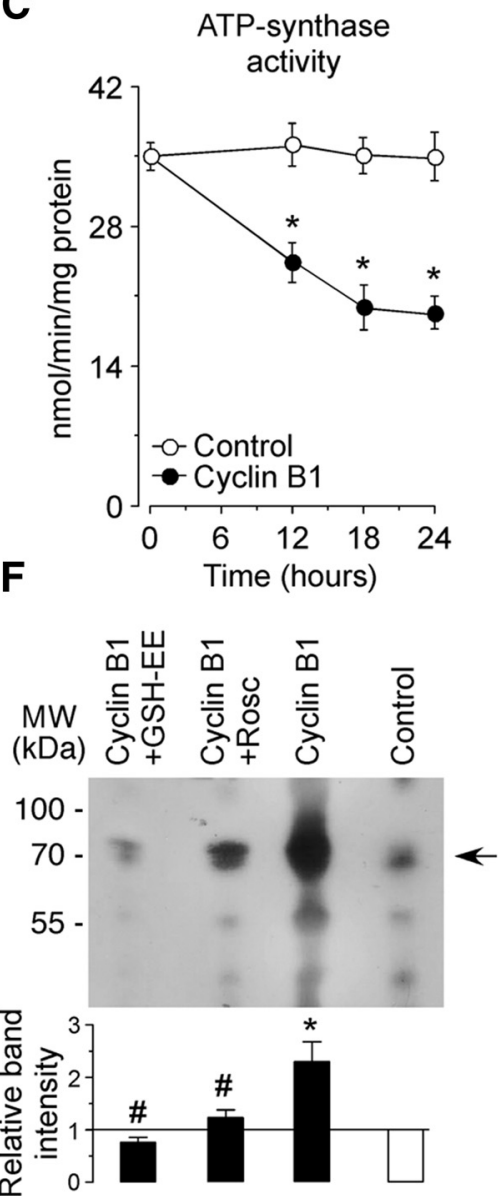

G

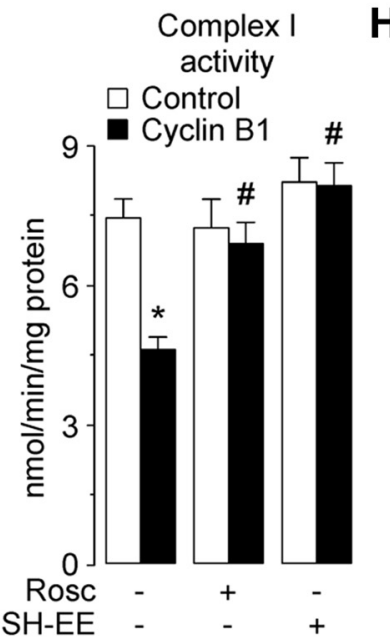

H

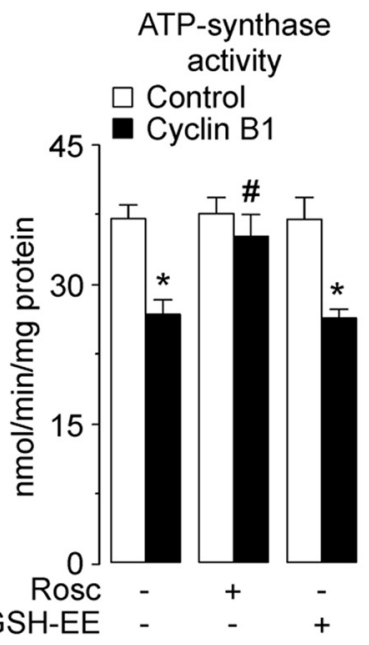

Figure 4. Cyclin B1-Cdk1 activation inhibits ATP synthase, leading to oxidative damage to complex I. HEK293T cells were transfected with $0.8 \mu \mathrm{g} / 10^{6}$ cells pIRES2-EGFP, either empty (Control; expressing GFP) or containing the full-length CDNA of human cyclin B1 (Cyclin B1; expressing both cyclin B1 and GFP). $A$, Western blots of cell extracts were probed sequentially with antibodies to cyclin B1, followed by GAPDH as loading control. A representative Western blot is shown of three. Bar graphs represent the relative cyclin B1 protein abundance compared with $0 \mathrm{~h}$ (immediately after transfection). Each bar represents the mean \pm SEM of three independent cell cultures $(n=3) .{ }^{*} p<0.05$ versus 0 h. $\boldsymbol{B}$, Mitochondrial complex I activity was measured by spectrometry at different times after transfections. ${ }^{*} p<0.05$ versus control. C, ATP synthase activity was measured by spectrometry at different times after transfections. ${ }^{*} p<0.05$ versus control. D, HEK293T cells were suspended in HBSS, and the rate of oxygen consumption was measured at different times after transfections by using with a Clark-type dissolved oxygen electrode. ${ }^{*} p<0.05$ versus control. $E$, $\Delta \psi_{\mathrm{m}}$ was assessed by flow cytometry in HEK293T at different times after transfections. ${ }^{*} p<0.05$ versus control. $\boldsymbol{F}$, HEK293T cells were transfected with $0.8 \mu \mathrm{g} / 10^{6}$ cells pIRES2-EGFP (control) or pIRES2- cyclin B1-EGFP (cyclin B1) either in the absence of presence of Rosc (10 $\mu \mathrm{M})$ and GSH-EE (1 mM) for $24 \mathrm{~h}$. Cyclin B1 induced complex I oxidation, as judged by the increase in oxidized proteins detected by immunoblotting from isolated biotin-NEM-labeled mitochondrial complex I subunits, which was abrogated by Rosc and GSH-EE. A representative Western blot is shown of three. Bar graphs represent the relative band intensity compared with control. Each bar represents the mean \pm SEM of three independent Western blots $(n=3)$. ${ }^{*} p<0.05$ versus control; ${ }^{\#} p<0.05$ versus cyclin B1. G, $\boldsymbol{H}$, HEK293T cells were transfected and treated as in $\boldsymbol{F}$. Mitochondrial complex l activity $(\boldsymbol{G})$ and ATP synthase activity $(\boldsymbol{H})$ were measured by spectrometry at $24 \mathrm{~h}$ after transfections. ${ }^{*} p<$ 0.05 versus control; $\# p<0.05$ versus cyclin $B 1$. In $\boldsymbol{B}-\boldsymbol{E}, \boldsymbol{G}$, and $\boldsymbol{H}$, data are expressed as the mean $\pm \mathrm{SEM}$, from three or four independent cell cultures $(n=3-4)$. MW, Molecular weight. 

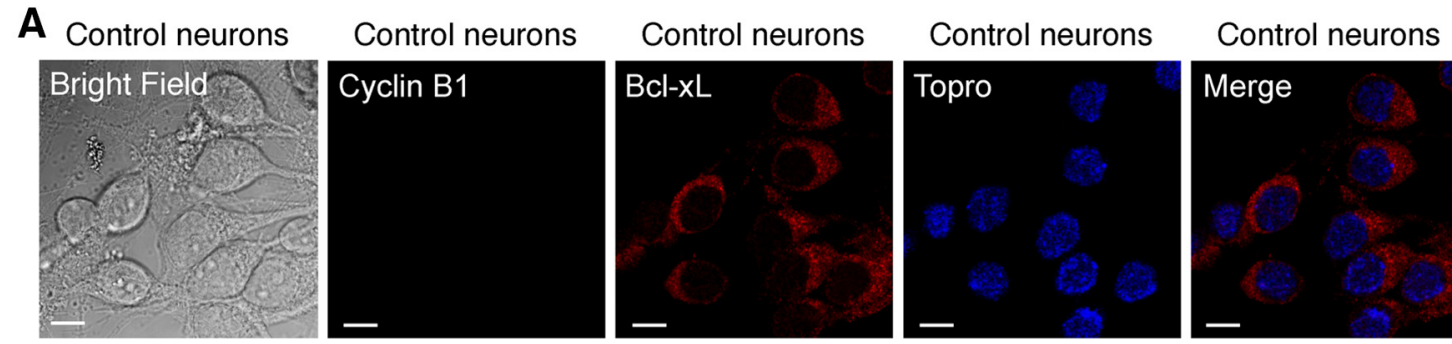

Glutamate neurons Glutamate neurons

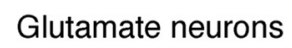

Glutamate neurons
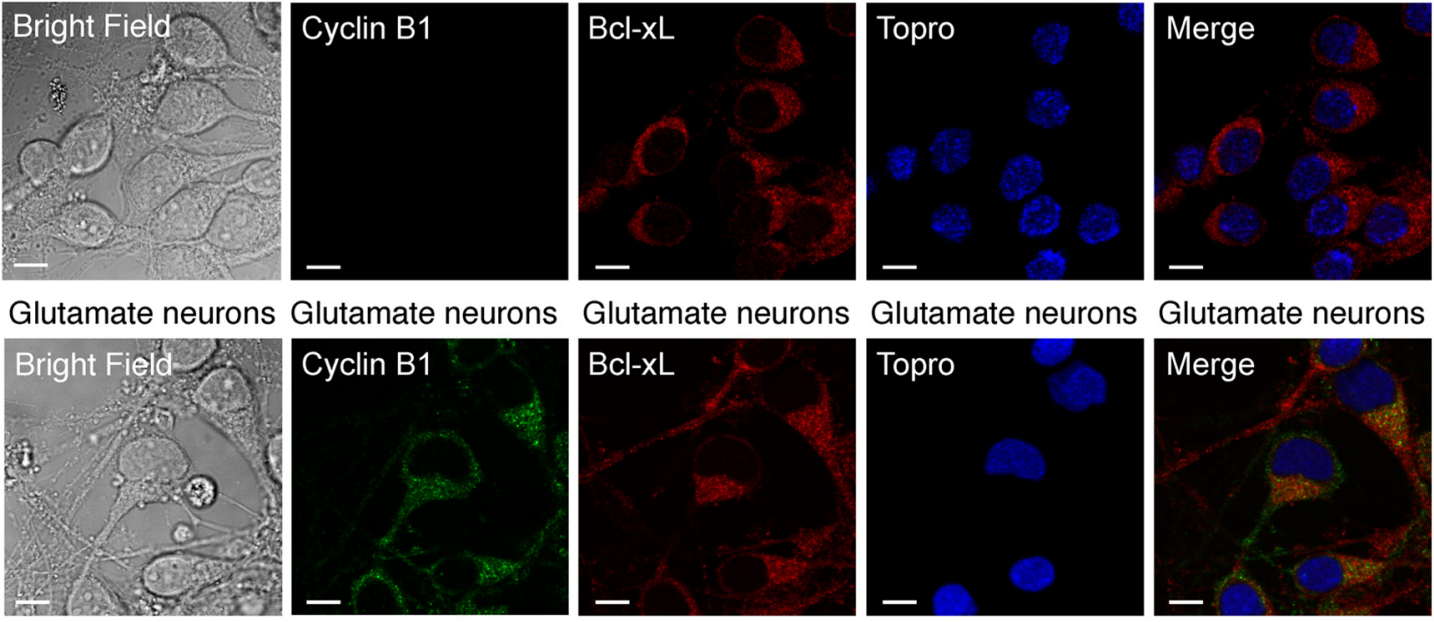

B
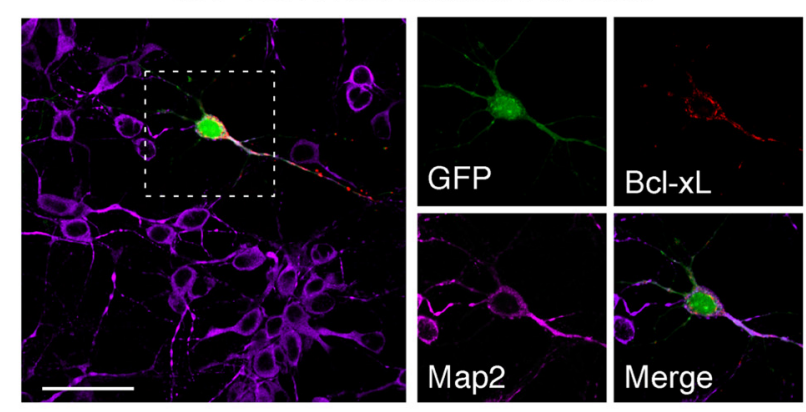

Cyclin B1-GFP-Bcl-xL-cotransfected neurons
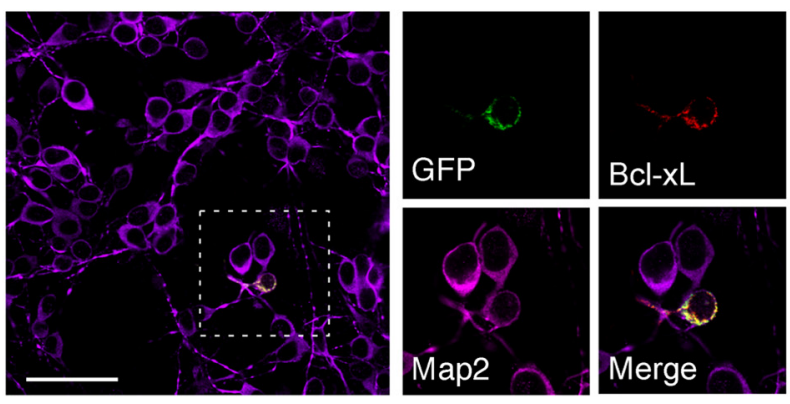

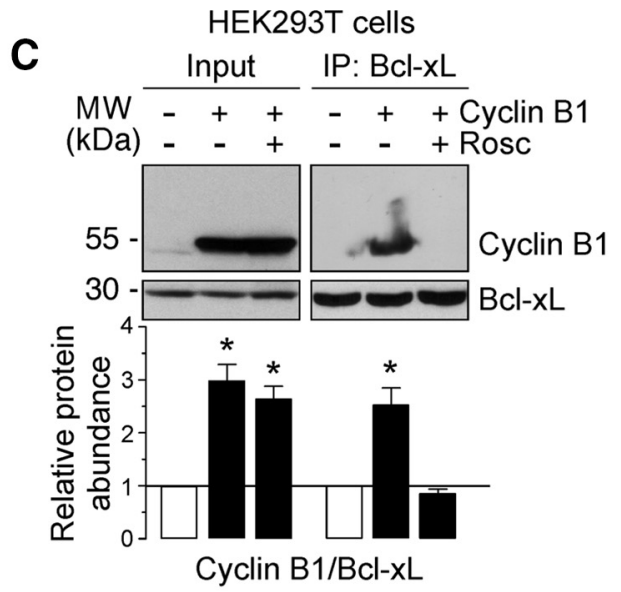

D

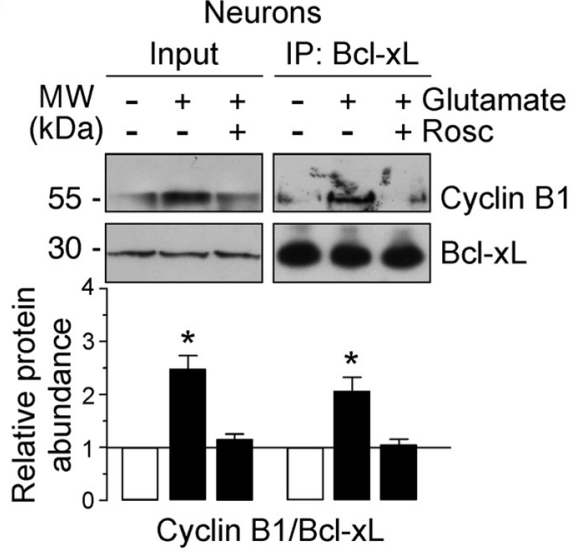

Figure 5. Cyclin B1-Cdk1 localizes to mitochondria in neurons on excitotoxic stimulus. $A$, Neurons were treated or not (control) with $100 \mu \mathrm{m}$ glutamate for 5 min and were further incubated in culture medium for 12-14h. Cyclin B1 and BCl-xL were detected by immunocytochemistry. Scale bars, $10 \mu \mathrm{m}$. Microphotograph reveals colocalization of cyclin B1 with BCl-xL in neurons. B, Neurons were cotransfected with plasmids encoding either GFP $\left(0.8 \mu \mathrm{m} / 10^{6}\right.$ cells pcDNA3-GFP; control) or cyclin B1 fused with GFP $\left(0.8 \mu \mathrm{m} / 10^{6}\right.$ cells pcDNA3-cyclin B1-GFP; cyclin B1-GFP) and Bcl-xL $\left(0.8 \mu \mathrm{m} / 10^{6}\right.$ cells p 8 -BCl-xL) for 12-14 h. Microphotograph reveals that cyclin B1-GFP, but not GFP (control), colocalizes with Bcl-xL. Neurons were immunostained with the neuronal marker Map2 (violet). Scale bars, $50 \mu \mathrm{m}$. C, HEK293T cells were transfected with $0.8 \mu \mathrm{g} / 10^{6}$ cells pIRES2-EGFP, either empty (-Cyclin B1) or containing the full-length cDNA of human cyclin B1 (Cyclin $B 1)$, in either the absence or presence of Rosc $(10 \mu \mathrm{m})$. At $24 \mathrm{~h}$ after transfections, cellular extracts were obtained and immunoprecipitated with anti-Bcl-xL antibody and analyzed by Western blot for cyclin B1 and BCl-xL. Of the whole cellular extracts used for immunoprecipitation, 10\% were loaded on SDS-PAGE as an input control. Coimmunoprecipitation assays revealed that cyclin B1 coprecipitated with BCl-xL. A representative Western blot is shown of three. Bar graphs represent the relative band intensity compared with control. Each bar represents the mean \pm SEM of three independent cell cultures $(n=3){ }^{*} p<0.05$ versus control ( - Cyclin B1). D, Neurons were treated or not ( - Glu) with $100 \mu \mathrm{m}$ glutamate for 5 min and were further incubated in culture medium for $20 \mathrm{~h}$, in either the absence or presence of Rosc $(10 \mu \mathrm{M})$. Coimmunoprecipitation assay was performed as indicated in C. Cyclin B1 coprecipitated with BCl-xL in neurons on excitotoxic stimulus. A representative Western blot is shown of three. Bar graphs represent the relative band intensity compared with control. Each bar represents the mean \pm SEM of three independent neuronal cultures $(n=3) .{ }^{*} p<0.05$ versus untreated $(-G l u)$ neurons. MW, Molecular weight. 
A

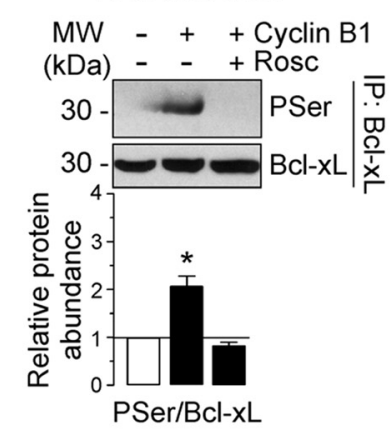

D

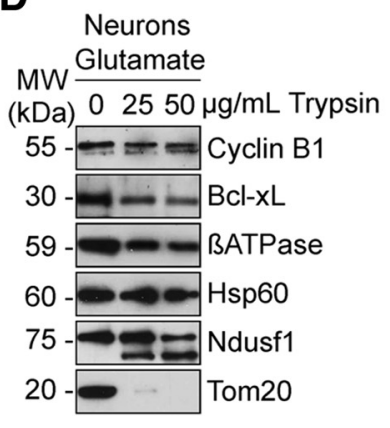

B

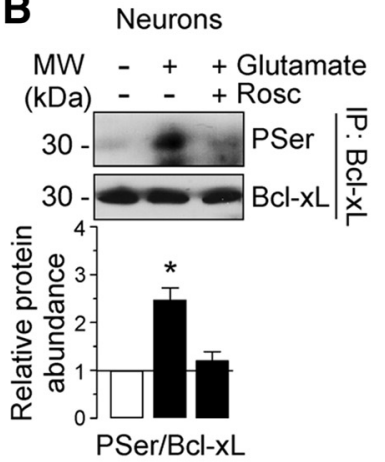

$\mathbf{E}$

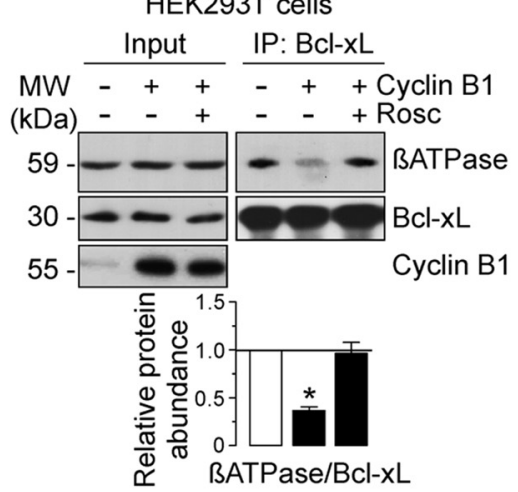

C

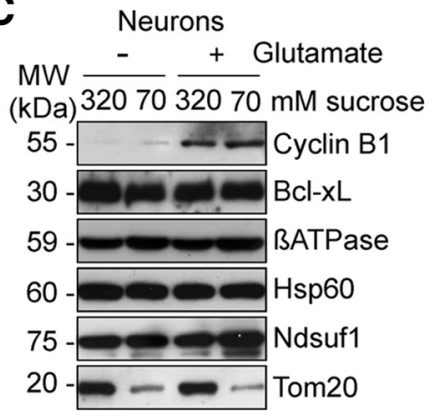

$\mathbf{F}$

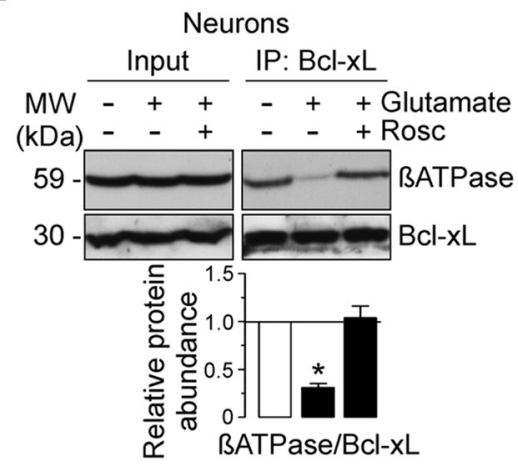

Figure 6. cyclin $\mathrm{B} 1-\mathrm{Cdk1}$ phosphorylates $\mathrm{BCl}-\mathrm{xL}$, leading to its dissociation from $\beta-\mathrm{F}_{1} \mathrm{~F}_{0}-\mathrm{ATP}$ synthase on the excitotoxic stimulus. $A$, HEK293T cells were transfected with $0.8 \mu \mathrm{g} / 10^{6}$ cells pIRES2-EGFP, either empty or containing the full-length CDNA of human cyclin B1, in either the absence of presence of Rosc $(10 \mu \mathrm{M})$. At $24 \mathrm{~h}$ after transfections, cellular extracts were obtained and immunoprecipitated with anti-BCl-xL antibody and analyzed by Western blot for phospho-Serine (PSer) and BCl-xL. Expression levels of cyclin B1 (Input) is shown in Figure 5C. B, Neurons were treated or not with $100 \mu \mathrm{m}$ glutamate for $5 \mathrm{~min}$ and were further incubated in culture medium for $20 \mathrm{~h}$. When indicated, Rosc (10 $\mu \mathrm{m})$ was added to the culture medium. Neuronal extracts were immunoprecipitated with anti-Bcl-xL antibody and analyzed by Western blot for phospho-Serine (PSer) and Bcl-xL. C, D, Neurons were exposed to glutamate as in $\boldsymbol{B}$, and submitochondrial localization of cyclin B1, BCl-xL, and $\beta-\mathrm{F}_{1} \mathrm{~F}_{0}-\mathrm{ATP}$ synthase was detected by mitoplasting $(\boldsymbol{C})$ and protease protection assay (D). C, Mitochondria isolated from untreated ( $-\mathrm{Glu}$ ) or glutamate-treated $(+$ Glu) neurons were incubated in isosmotic $(320 \mathrm{~mm}$ ) or hypotonic ( $70 \mathrm{~mm}$ ) sucrose buffer, and extracts were subjected to Western blot analysis with cyclin B1, BCl-xL, $\beta$-ATPase, Hsp60 (a matrix protein), Ndusf1 (and inner membrane protein), and Tom 20 (an outer membrane protein). $\boldsymbol{D}$, Mitochondria isolated from glutamate-treated neurons were incubated in mitochondrial buffer with or without 25 or $50 \mu \mathrm{g} / \mathrm{ml}$ soybean trypsin. Extracts were analyzed by immunoblotting with indicated antibodies. $\boldsymbol{E}$, HEK293T cells were transfected as described in $\boldsymbol{A}$. Cellular extracts were immunoprecipitated with anti-BCl-xL antibody and analyzed by Western blot for $\beta-\mathrm{F}_{1} \mathrm{~F}_{0}-\mathrm{ATP}$ synthase ( $\beta$ ATPase) and BCl-xL. of the whole cellular extracts used for immunoprecipitation, $10 \%$ were loaded on SDS-PAGE as an input control. Coimmunoprecipitation assays revealed that $\beta-\mathrm{F}_{1} \mathrm{~F}_{0}-$ ATP synthase failed to coprecipitate with Bcl-xL in cyclin B1-transfected cells, which was prevented by Rosc. $\boldsymbol{F}$, Neurons were exposed to glutamate as in $\boldsymbol{B}$, and neuronal extracts were immunoprecipitated as in $\boldsymbol{E}$. Coimmunoprecipitation assays revealed that glutamate avoided $\beta$ - $\boldsymbol{F}_{1} \boldsymbol{F}_{0}-A T P$ synthase and $\mathrm{BCl}$-xL interaction in neurons, which was prevented by Rosc. In $\boldsymbol{A}, \boldsymbol{B}, \boldsymbol{E}$, and $\boldsymbol{F}$, a representative Western blot is shown of three. Bar graphs represent the relative band intensity compared with - Cyclin B1 $(\boldsymbol{A}, \boldsymbol{E})$ or $-\mathrm{Glu}(\boldsymbol{B}, \boldsymbol{F})$. Each bar represents the mean \pm SEM of three independent cell $(\boldsymbol{A}, \boldsymbol{E})$ or neuronal $(\boldsymbol{B}, \boldsymbol{F})$ cultures $(n=3) .{ }^{*} p<0.05$ versus - Cyclin $B 1(\boldsymbol{A}, \boldsymbol{E})$ or $-\mathrm{Glu}(\boldsymbol{B}, \boldsymbol{F})$. MW, Molecular weight.

treated neurons using trypsin to digest exposed proteins. As showed in Figure $6 D$, similarly to Hsp60 and Ndusf1, but unlike Tom 20 , cyclin $\mathrm{B} 1, \mathrm{Bcl}-\mathrm{xL}$, and $\beta-\mathrm{F}_{1} \mathrm{~F}_{\mathrm{o}}-\mathrm{ATP}$ synthase were protected from the trypsin digestion. These data demonstrate that cyclin $\mathrm{B} 1, \mathrm{Bcl}-\mathrm{xL}$, and $\beta-\mathrm{F}_{1} \mathrm{~F}_{\mathrm{o}}-\mathrm{ATP}$ synthase colocalize in the mitochondrial compartment, either inner membrane or matrix, on a neuronal excitotoxic stimulus.

Next, the interaction between Bcl-xL and $\beta-\mathrm{F}_{1} \mathrm{~F}_{\mathrm{o}}-\mathrm{ATP}$ synthase ( $\beta$ ATPase) was analyzed in neurons during an excitotoxic stress. The interaction of Bcl-xL with $\beta$ ATPase was disrupted by either exogenously expressed cyclin B1 in HEK293T cells (Fig. $6 E$ ) or by endogenous cyclin $\mathrm{B} 1$, accumulated during excitotoxic stress (Fig. $6 F$ ). Rosc rescued the cyclin B1-Cdk1-mediated Bcl$\mathrm{xL}-\beta$ ATPase interaction (Fig. $6 E, F$ ). These data indicate that glutamate-mediated cyclin B1-Cdk1 activation promotes Bcl-xL phosphorylation, resulting in its dissociation from $\beta-\mathrm{F}_{1} \mathrm{~F}_{\mathrm{o}}-\mathrm{ATP}$ synthase. To elucidate whether such a mechanism elicits any functional consequence on ATP synthase activity, we performed site-directed mutagenesis to generate $\mathrm{Bcl}-\mathrm{xL}(\mathrm{D})$ and $\mathrm{Bcl}-\mathrm{xL}(\mathrm{A})$ (Abbott et al., 1986). Because Ser-62 in Bcl-xL is a high score putative phosphorylation target of Cdk1 (Terrano et al., 2010), we decided to mutate this residue. HEK293T cells were cotransfected with cyclin $\mathrm{B} 1$ together with either $\mathrm{Bcl}-\mathrm{xL}(\mathrm{A})$ or Bcl$\mathrm{xL}(\mathrm{D})$. We first confirmed that the phosphodefective $\mathrm{Bcl}-\mathrm{xL}$ mutant $\mathrm{Bcl}-\mathrm{xL}(\mathrm{A})$ was not phosphorylated by cyclin B1-Cdk1 (Fig. 7A). As revealed by the coimmunoprecipitation assay, $\beta$ ATPase interacted with the phosphodefective, but not with the phosphomimetic, Bcl-xL mutant (Fig. 7B). Furthermore, the expression of the phosphodefective, but not the phosphomimetic, $\mathrm{Bcl}-\mathrm{xL}$ mutant in neurons restored the interaction of $\mathrm{Bcl}-\mathrm{xL}$ with the $\beta-\mathrm{F}_{1} \mathrm{~F}_{\mathrm{o}}-\mathrm{ATP}$ synthase on the excitotoxic stimulus (Fig. $7 \mathrm{C}$ ). These results demonstrate that glutamate-induced $\mathrm{Bcl}-\mathrm{xL}$ phosphorylation at Ser42 disrupts the Bcl-xL- $\beta$-subunit interaction, hence explaining the mechanism of the previously reported inhibition of ATP synthase activity (Alavian et al., 2011). In fact, expression of the phosphodefective Bcl-xL (Fig. 7D) mutant form exerted a dominant-negative effect, because it was unable to inhibit ATP synthase activity during cyclin B1 expression (Fig. 7E). However, expression of the phosphomimetic form (Fig. 7D) imitated the effect of endogenous Bcl-xL at inhibiting ATP synthase 


\section{A HEK293T cells}

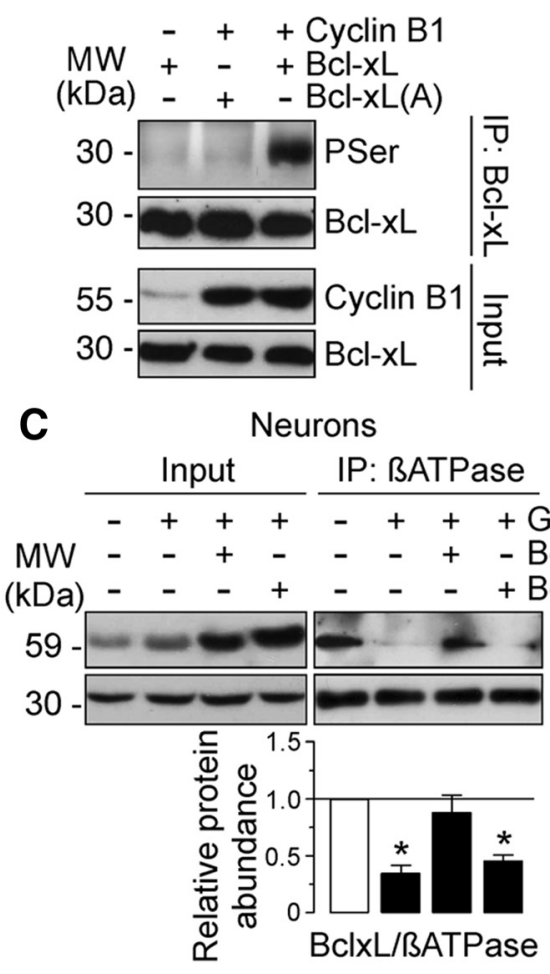

\section{HEK293T cells}

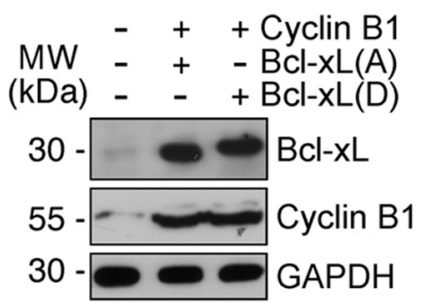

B

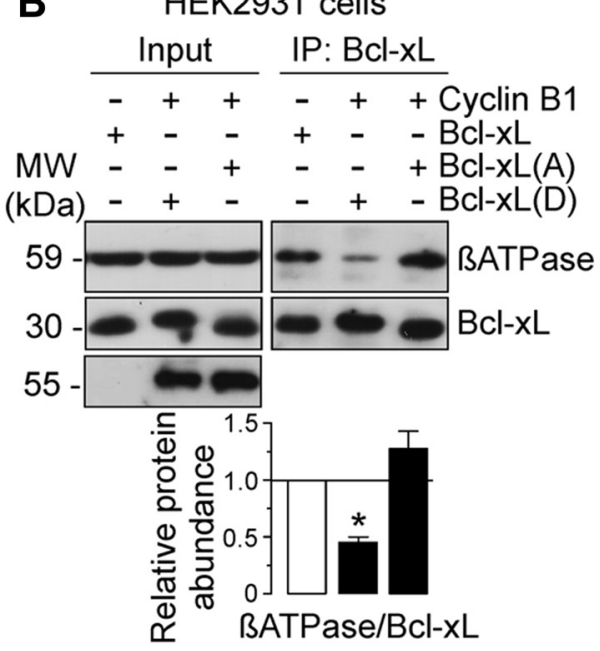

$\mathrm{BCl}-\mathrm{XL}$ BATPase

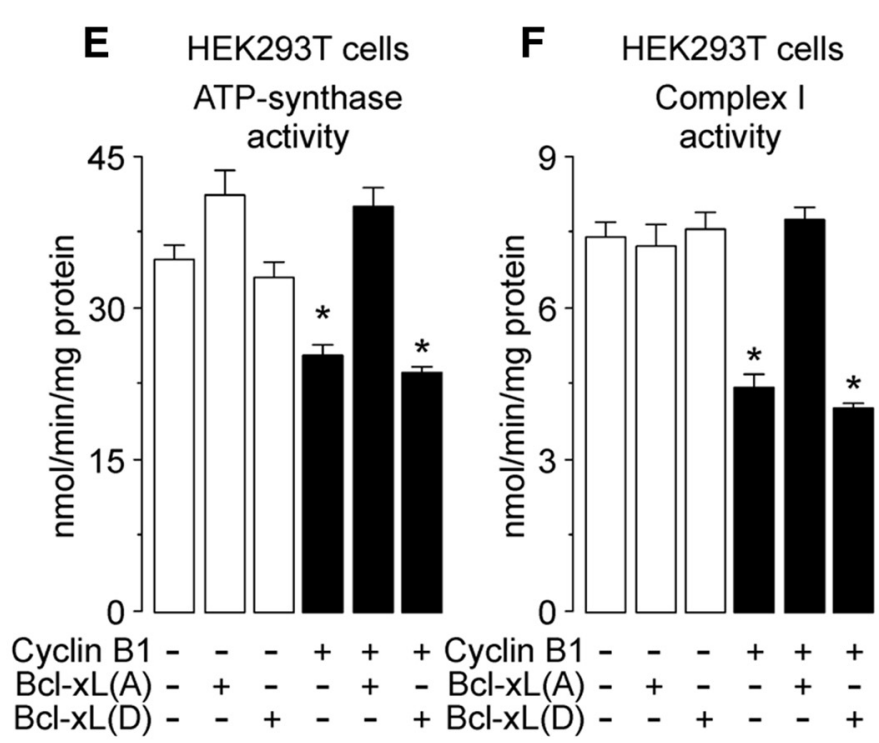

Figure 7. Cyclin B1-Cdk1-induced Bcl-xL phosphorylation leading to its dissociation from $\beta-\mathrm{F}_{1} \mathrm{~F}_{0}-A T P$ synthase causes ATP synthase and complex I inhibition on the excitotoxic stimulus. $A$, HEK293T cells were cotransfected with $0.8 \mu \mathrm{g} / 10^{6}$ cells plRES2-EGFP, either empty (Control) or containing the full-length (DNA of human cyclin B1, together with $0.8 \mu \mathrm{g} / 10^{6}$ cells P8, either empty (Control) or containing the full-length CDNA of human BCl-xL, the phosphodefective BCl-xL(A) or the phosphomimetic BCl-xL(D) Ser62-BCl-xL mutants. Cell extracts were immunoprecipitated with anti-BCl-xL antibody and analyzed by Western blot for phospho-Serine (PSer) and BCl-XL. B, HEK293T cells were cotransfected as in $\boldsymbol{B}$. Coimmunoprecipitation assay revealed that $\beta$ ATPase coprecipitated with $B C l-x L(A)$ but not with BCl-xL(D). C, Neurons were transfected with $0.8 \mu \mathrm{g} / 10^{6}$ cells P8, either empty or containing the full-length CDNA of human phosphodefective BCl-xL(A) or phosphomimetic $B C l-x L(D)$ Ser62-BCl-xL mutants. Neurons were then treated or not $(-G l u)$ with $100 \mu \mathrm{m}$ glutamate for $5 \mathrm{~min}$ and were further incubated in culture medium for $20 \mathrm{~h}$. Coimmunoprecipitation assay reveals that the $\mathrm{BCl}-\mathrm{xL}(\mathrm{A})$, but not the $\mathrm{BCl}-\mathrm{xL}(\mathrm{D})$, mutant restored the interaction of $\mathrm{BCl}-\mathrm{xL}$ with the $\beta-\mathrm{F}_{1} \mathrm{~F}_{0}-\mathrm{ATP}$ synthase in neurons on the excitotoxic stimulus. In $B$ and $\boldsymbol{C}$, a representative Western blot is shown of three. Bar graphs represent the relative band intensity compared with $-\mathrm{Cyclin} B 1(\boldsymbol{B})$ or $-\mathrm{Glu}(\boldsymbol{C})$. Each bar represents the mean \pm SEM of three independent cell (B) or neuronal $(\boldsymbol{C})$ cultures $(n=3) .{ }^{*} p<0.05$ versus - Cyclin B1 (B) or - Glu (C). $\boldsymbol{E}, \boldsymbol{F}$, HEK293T cells were cotransfected as in $\boldsymbol{B}$. The expression of BCl-xL(A), but not BCl-xL(D), fully prevented inhibition of ATP synthase $(\boldsymbol{E})$ and complex I $(\boldsymbol{F})$ activities in cyclin B1-expressing cells. ${ }^{*} p<0.05$ versus - Cyclin B1. Data are expressed as the mean \pm SEM of three independent cell cultures $(n=3)$. MW, Molecular weight.

activity (Fig. 7E). These results indicate that cyclin B1-Cdk1 mediated phosphorylation of $\mathrm{Bcl}-\mathrm{xL}$ at Ser62, triggering its dissociation from $\beta$ ATPase, is sufficient to inhibit ATP synthase activity. Finally, we aimed to elucidate whether inhibition of ATP synthase activity in this manner accounted for complex I inactivation. As shown in Figure 7F, the inhibition of complex I activity caused by cyclin B1 was abolished by coexpressing the phosphodefective, but not the phosphomimetic, form of Bcl-xL. Thus, ATP synthase inhibition by cyclin B1-Cdk1 is sufficient to promote complex I impairment.
Cyclin B1-Cdk1-induced Bcl-xL phosphorylation accounts for oxidative stress and mitochondrial dysfunction on excitotoxic stimulus

We finally sought to ascertain whether Bcl-xL phosphorylation is essential in the signaling cascade leading to oxidative stress, $\Delta \psi_{\mathrm{m}}$ collapse, and neuronal apoptotic death during glutamate excitotoxicity. To do so, we used either exogenously expressed cyclin B1 or endogenously accumulated cyclin B1 during glutamate treatment, both in neurons. We found that expression of the phosphodefective mutant form of $\mathrm{Bcl}-\mathrm{xL}$ fully prevented the increase 
A

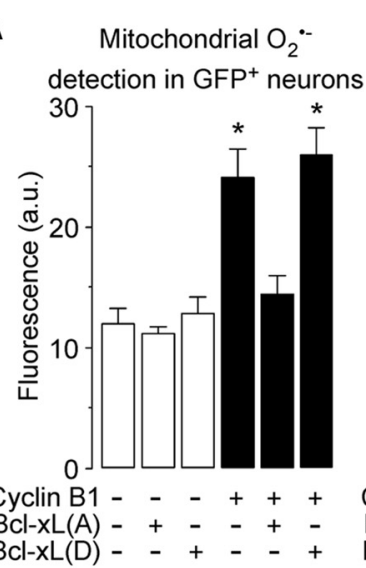

B<smiles>C1CCCCC1</smiles>

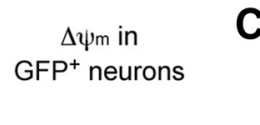

C

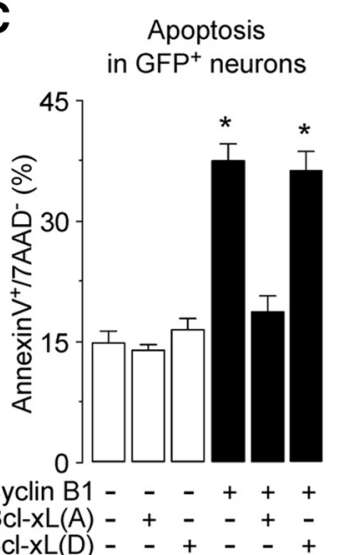

D

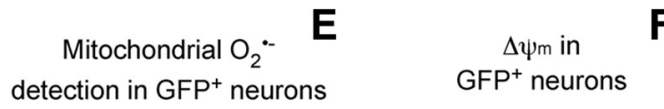

$\mathbf{F}$ $\mathrm{GFP}^{+}$neurons

Apoptosis in $\mathrm{GFP}^{+}$neurons
G
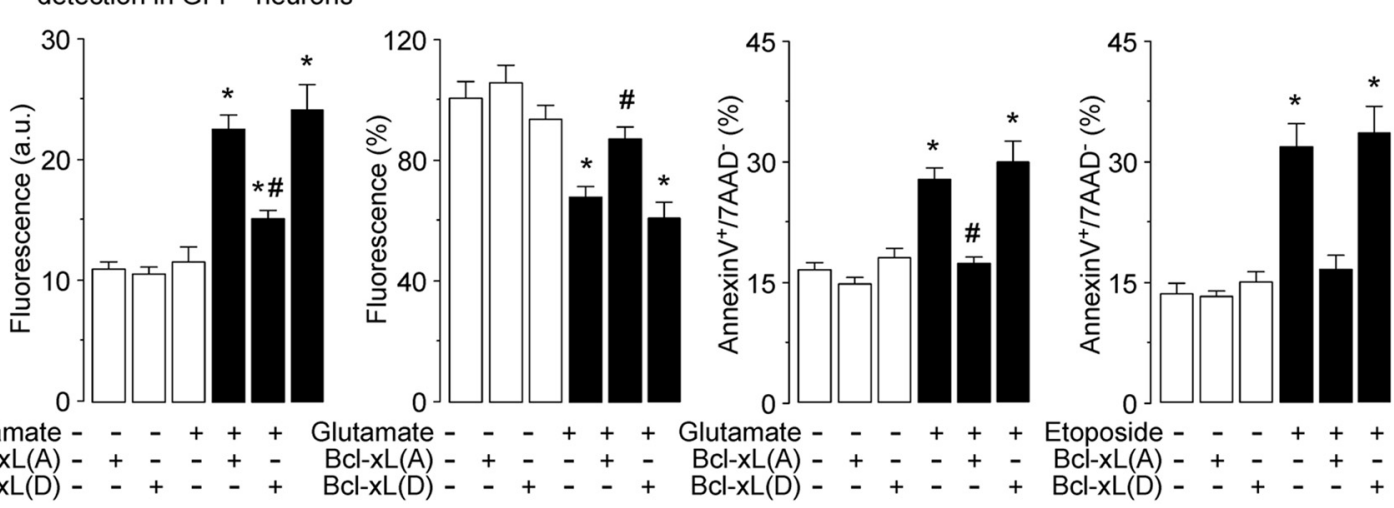

Apoptosis in $\mathrm{GFP}^{+}$neurons

Figure 8. Cyclin B1-Cdk1-induced BCl-xL phosphorylation accounts for oxidative stress and mitochondrial dysfunction on the excitotoxic stimulus. $A-C$, Neurons cells were cotransfected with 0.8 $\mu \mathrm{g} / 10^{6}$ cells plRES2-EGFP, either empty (Control) or containing the full-length CDNA of human cyclin B1, together with $0.8 \mu \mathrm{g} / 10^{6}$ cells P8, either empty (Control) or containing the full-length CDNA of human phosphodefective $B C l-x L(A)$ or phosphomimetic, $B C l-x L(D)$ Ser62-BCl-xL mutants. Mitochondrial $0_{2}^{--}$generation $(A)$, mitochondrial membrane potential $\left(\Delta \psi_{\mathrm{m}}\right)(B)$, and neuronal apoptotic death (annexin $\mathrm{V}^{+} / 7-\mathrm{AAD}^{-}$neurons) $(\boldsymbol{C})$ were assayed by flow cytometry in transfected (GFP ${ }^{+}$) neurons. The expression of $\mathrm{BCl}-\mathrm{xL}(\mathrm{A})$, but not $\mathrm{BCl}-\mathrm{xL}(\mathrm{D})$, prevented cyclin $\mathrm{B} 1$-induced oxidative stress $(\boldsymbol{A}), \Delta \psi \mathrm{m}$ loss $(\boldsymbol{B})$, and apoptosis $(\boldsymbol{C})$ in neurons. ${ }^{*} p<0.05$ versus - Cyclin B1 (control). $\boldsymbol{D}-\boldsymbol{F}$, Neurons were transfected with $0.8 \mu \mathrm{g} / 10^{6}$ cells $\mathrm{P} 8$, either empty $($ control) or containing human phosphodefective BCl-xL(A) or phosphomimetic BCl-xL(D) Ser62-Bcl-xL mutants. Neurons were then treated or not ( $-G l u)$ with $100 \mu \mathrm{m}$ glutamate for 5 min and were further incubated in culture medium for $20 \mathrm{~h}$. The expression of $B \mathrm{Cl}-\mathrm{xL}(\mathrm{A})$, but not $\mathrm{BCl}-\mathrm{xL}(\mathrm{D})$, prevented glutamate-induced oxidative stress $(\boldsymbol{D}), \Delta \psi \mathrm{m}$ loss $(\boldsymbol{E})$, and apoptosis $(\boldsymbol{F})$ in neurons. ${ }^{*} p<0.05$ versus - Glu (control); $\# p<0.05$ versus glutamate. G, Neurons were transfected as in $\boldsymbol{D}$ and then were exposed to etoposide (10 $\mu \mathrm{m})$ for $24 \mathrm{~h}$. The expression of BCl-xL(A), but not BCl-xL(D), prevented glutamate-induced neuronal apoptosis. ${ }^{*} p<0.05$ versus - Etoposide (control). In all cases, data are expressed as the mean \pm SEM of three or four independent neuronal cultures $(n=3-4)$.

in mitochondrial $\mathrm{O}_{2}^{--}$(Fig. $8 A$ ), $\Delta \psi_{\mathrm{m}}$ collapse (Fig. $8 B$ ), and apoptotic death (Fig. 8 C) triggered by cyclin B1. However, these phenomena were unaffected by expression of the phosphomimetic form of Bcl-xL (Fig. 8A-C). Furthermore, glutamatemediated increase in mitochondrial $\mathrm{O}_{2}^{-}$(Fig. $8 D$ ), $\Delta \psi_{\mathrm{m}}$ collapse (Fig. $8 E$ ), and apoptotic death (Fig. $8 F$ ) were prevented by expressing the phosphodefective Bcl-xL mutant but not by its phosphomimetic form (Fig. $8 D-F$ ). These results indicate that Ser62 phosphorylation of $\mathrm{Bcl}-\mathrm{xL}$ accounts for oxidative stress, mitochondrial dysfunction, and the proapoptotic effect of cyclin B1Cdk1 in excitotoxicity. To further confirm this, we assessed whether Ser62 mutants affected the anti-apoptotic function of Bcl-xL. To do so, we expressed its phosphodefective (A) mutant, which fully prevented etoposide-induced neuronal apoptosis (Fig. 8G). Conversely, expression of its phosphomimetic (D) form failed to protect neurons from etoposide-mediated neurotoxicity. These data are in good agreement with previous findings showing that $\mathrm{Bcl}-\mathrm{xL}$ is phosphorylated at residue Ser62, hence abolishing its anti-apoptotic function, in response to anti-mitotic drugs in cancer cells (Schmitt et al., 2007; Upreti et al., 2008; Antony et al., 2010).

\section{Discussion}

We have shown previously that an excitotoxic challenge by overactivation of NMDA receptors triggers the stabilization of cyclin B1 because of a cascade of events involving $\mathrm{Ca}^{2+}$-mediated activation of calpain to breakdown p35 into p25, which strongly activated Cdk5 activity in the nucleus (Maestre et al., 2008). Active Cdk5 hyperphosphorylated Cdh1, leading to its dissociation from $\mathrm{APC} / \mathrm{C}$, which causes the inhibition of Cdh1 ability to coactivate APC/C (Jaquenoud et al., 2002; Maestre et al., 2008). Here, we now demonstrate that the stabilization of cyclin B1 after this excitotoxic challenge occurs selectively in mitochondria. In a previous work, forced expression of a mutant form of cyclin B1 harboring a mitochondrial leading sequence in dividing cells exerted the coordination of the mitochondrial respiration with cellcycle progression, especially the $\mathrm{G}_{2} / \mathrm{M}$ transition (Wang et al., 2014). However, recruitment of endogenous cyclin B1, as we herein show, has not been reported so far. This result is intriguing, because naive cyclin B1 apparently lacks a mitochondrial leading sequence. In addition, postmitotic neurons do not need to exert this coordination (Wang et al., 2014), which is an exclu- 
sive function of proliferating cells. Thus, the mechanism whereby cyclin B1 specifically recruits to mitochondria and the consequence(s) of such a subcellular localization remain unknown.

We show that Cdk1 is responsible for the recruitment of cyclin B1 to mitochondria, because both proteins colocalize in the organelle. Furthermore, because we found that Bcl-xL phosphorylated at Ser62, i.e., its Cdk1-cognate phosphorylating residue (Terrano et al., 2010), the formation of a cyclin B1-Cdk1 complex in mitochondria is highly likely. In good agreement with previous studies performed in cancer cells (Schmitt et al., 2007; Upreti et al., 2008; Antony et al., 2010), phosphorylation at Ser62 lost the anti-apoptotic activity of Bcl-xL in neurons, suggesting its involvement in mitochondrial dysfunction during glutamate treatment. However, because its phosphomimetic form failed to affect mitochondrial membrane potential and oxidative stress, additional mechanisms cannot be disregarded. Bcl-xL is known to interact with the $\beta$ subunit of the $\mathrm{F}_{1} \mathrm{~F}_{\mathrm{o}}-\mathrm{ATP}$ synthase to form a stable complex and maximize the efficiency of production of ATP (Alavian et al., 2011). Here, we show that phosphorylation of Ser62 in Bcl-xL is sufficient to promote its dissociation from the $\beta$ subunit of the $\mathrm{F}_{1} \mathrm{~F}_{\mathrm{o}}$-ATP synthase, leading to inhibition of ATP synthase enzymatic activity. Inhibition of ATP synthase activity is known to affect the $\Delta \psi_{\mathrm{m}}$ (Brand et al., 2004; Sánchez-Cenizo et al., 2010; Formentini et al., 2014). In fact, in our hands, glutamate exerted a cyclin B1-mediated biphasic effect on $\Delta \psi_{\mathrm{m}}$, namely a transient increase followed by a delayed collapse. During the increased $\Delta \psi_{\mathrm{m}}$ phase, the mitochondrial respiratory chain is known to stimulate $\mathrm{O}_{2}^{--}$(Sánchez-Cenizo et al., 2010; Formentini et al., 2014), which we found in neurons on the excitotoxic stimulus. Mitochondrial complex I contains $\mathrm{O}_{2}^{--}$-sensitive Fe-S clusters (Sazanov, 2014) and specific cysteine residues (Chouchani et al., 2013) that are essential for optimal electron transfer toward ubiquinone. Accordingly, an increased production of $\mathrm{O}_{2}^{--}$, by either complex I or complex III (Murphy, 2009), caused both delayed oxidative damage to complex I and impairment in the electron transfer likely responsible for the inhibition of its activity. This effect had functional consequences for the intact cell, because both $\Delta \psi_{\mathrm{m}}$ was lost in a delayed manner, and the rate of $\mathrm{O}_{2}$ consumption was impaired dramatically.

The delayed collapse in $\Delta \psi_{\mathrm{m}}$ observed under our conditions is likely attributable to the inefficacy of complex I at pumping protons into the intermembrane space, a trigger of the mitochondrial transition pore. It has been shown recently that this pore is formed by dimerization of $\mathrm{F}_{1} \mathrm{~F}_{\mathrm{o}}$-ATP synthase $\beta$ subunits (Carraro et al., 2014). Thus, dissociation of phosphorylated Bcl-xL from the $\mathrm{F}_{1} \mathrm{~F}_{\mathrm{o}}-\mathrm{ATP}$ synthase $\beta$ subunits that we herein describe might be an important step in this process by allowing free $\mathrm{F}_{1} \mathrm{~F}_{\mathrm{o}}-$ ATP synthase $\beta$ subunits to dimerize. Subsequent opening of the mitochondrial transition pore will initiate mitochondrial outer membrane permeabilization to promote the release of proapoptotic factors (Galluzzi et al., 2009; Bernardi, 2013), shown previously to be sensitive to $\mathrm{Bcl}$-xL binding to the $\mathrm{F}_{1} \mathrm{~F}_{\mathrm{o}}-\mathrm{ATP}$ synthase $\beta$ subunit (Chen et al., 2011; Alavian et al., 2014).

In conclusion, here we decipher a cascade of events triggered by the overactivation of glutamate receptors in neurons, an underlying feature of several neurological diseases. This transduction pathway requires mitochondrial cyclin B1 to activate Cdk1 to promote phosphorylation of anti-apoptotic Bcl-xL. Phosphorylated Bcl-xL releases the $\beta$ subunit of $\mathrm{F}_{1} \mathrm{~F}_{\mathrm{o}}-\mathrm{ATP}$ synthase, likely forming the transition pore that promotes apoptosis. This mechanism can account for the known deleterious effects of cyclin B1 accumulation in the degenerating brain areas of neurological diseases (Vincent et al., 1997; Love, 2003; Yang et al., 2003). Further- more, the negative regulation of mitochondrial function by cyclin B1-Cdk1 activity that we describe here may have implications beyond the neural tissue. For instance, it is known that cancer cells upregulate aerobic glycolytic metabolism to support aberrant cell proliferation (Vander Heiden et al., 2009), which is coupled with decreased APC/C-Cdh1 activity (Almeida et al., 2010; Moncada et al., 2012). The aberrantly accumulated cyclin B1 in mitochondria causing inhibition of complex I impairs the energetic efficiency of mitochondria, and this would likely stimulate glycolysis in proliferating cells. The combination of such a metabolic switch with the abnormal ability of cancer cells to form the transition pore (Brenner and Grimm, 2006; Javadov et al., 2011) would represent a previously unrecognized mechanism whereby cyclin B1-Cdk1 promotes cancer cell progression.

\section{References}

Abbott WA, Griffith OW, Meister A (1986) Gamma-glutamyl-glutathione. Natural occurrence and enzymology. J Biol Chem 261:13657-13661. Medline

Alavian KN, Li H, Collis L, Bonanni L, Zeng L, Sacchetti S, Lazrove E, Nabili P, Flaherty B, Graham M, Chen Y, Messerli SM, Mariggio MA, Rahner C, McNay E, Shore GC, Smith PJ, Hardwick JM, Jonas EA (2011) Bcl-xL regulates metabolic efficiency of neurons through interaction with the mitochondrial F1FO ATP synthase. Nat Cell Biol 13:1224-1233. CrossRef Medline

Alavian KN, Beutner G, Lazrove E, Sacchetti S, Park HA, Licznerski P, Li H, Nabili P, Hockensmith K, Graham M, Porter GA Jr, Jonas EA (2014) An uncoupling channel within the c-subunit ring of the F1FO ATP synthase is the mitochondrial permeability transition pore. Proc Natl Acad Sci U S A 111:10580-10585. CrossRef Medline

Almeida A, Bolaños JP (2001) A transient inhibition of mitochondrial ATP synthesis by nitric oxide synthase activation triggered apoptosis in primary cortical neurons. J Neurochem 77:676-690. CrossRef Medline

Almeida A, Medina JM (1998) A rapid method for the isolation of metabolically active mitochondria from rat neurons and astrocytes in primary culture. Brain Res Brain Res Prot 2:209-214. CrossRef

Almeida A, Almeida J, Bolaños JP, Moncada S (2001) Different responses of astrocytes and neurons to nitric oxide: the role of glycolytically-generated ATP in astrocyte protection. Proc Natl Acad Sci U S A 98:15294-15299. CrossRef Medline

Almeida A, Bolaños JP, Moreno S (2005) Cdh1/Hct1-APC is essential for the survival of postmitotic neurons. J Neurosci 25:8115-8121. CrossRef Medline

Almeida A, Bolaños JP, Moncada S (2010) E3 ubiquitin ligase APC/C-Cdh1 accounts for the Warburg effect by linking glycolysis to cell proliferation. Proc Natl Acad Sci U S A 107:738-741. CrossRef Medline

Antony R, Lukiw WJ, Bazan NG (2010) Neuroprotectin D1 induces dephosphorylation of $\mathrm{Bcl}-\mathrm{xL}$ in a PP2A-dependent manner during oxidative stress and promotes retinal pigment epithelial cell survival. J Biol Chem 285:18301-18308. Medline

Bernardi P (2013) The mitochondrial permeability transition pore: a mystery solved? Front Physiol 4:95. CrossRef Medline

Billen LP, Kokoski CL, Lovell JF, Leber B, Andrews DW (2008) Bcl-XL inhibits membrane permeabilization by competing with Bax. PLoS Biol 6:e147. CrossRef Medline

Bolaños JP, Moro MA, Lizasoain I, Almeida A (2009) Mitochondria and reactive oxygen and nitrogen species in neurological disorders and stroke: therapeutic implications. Adv Drug Deliv Rev 61:1299-1315. CrossRef Medline

Brand MD, Affourtit C, Esteves TC, Green K, Lambert AJ, Miwa S, Pakay JL, Parker N (2004) Mitochondrial superoxide: production, biological effects, and activation of uncoupling proteins. Free Radic Biol Med 37:755767. CrossRef Medline

Brenner C, Grimm S (2006) The permeability transition pore complex in cancer cell death. Oncogene 25:4744-4756. CrossRef Medline

Carraro M, Giorgio V, Šileikyte J, Sartori G, Forte M, Lippe G, Zoratti M, Szabò I, Bernardi P (2014) Channel formation by yeast F-ATP synthase and the role of dimerization in the mitochondrial permeability transition. J Biol Chem 289:15980-15985. CrossRef Medline

Chen YB, Aon MA, Hsu YT, Soane L, Teng X, McCaffery JM, Cheng WC, Qi 
B, Li H, Alavian KN, Dayhoff-Brannigan M, Zou S, Pineda FJ, O'Rourke B, Ko YH, Pedersen PL, Kaczmarek LK, Jonas EA, Hardwick JM (2011) $\mathrm{Bcl}-\mathrm{xL}$ regulates mitochondrial energetics by stabilizing the inner membrane potential. J Cell Biol 195:263-276. CrossRef Medline

Chouchani ET, Methner C, Nadtochiy SM, Logan A, Pell VR, Ding S, James AM, Cochemé HM, Reinhold J, Lilley KS, Partridge L, Fearnley IM, Robinson AJ, Hartley RC, Smith RA, Krieg T, Brookes PS, Murphy MP (2013) Cardioprotection by S-nitrosation of a cysteine switch on mitochondrial complex I. Nat Med 19:753-759. CrossRef Medline

De Azevedo WF, Leclerc S, Meijer L, Havlicek L, Strnad M, Kim SH (1997) Inhibition of cyclin-dependent kinases by purine analogues: crystal structure of human cdk2 complexed with roscovitine. Eur J Biochem 243:518526. CrossRef Medline

Ding J, Mooers BH, Zhang Z, Kale J, Falcone D, McNichol J, Huang B, Zhang XC, Xing C, Andrews DW, Lin J (2014) After embedding in membranes antiapoptotic Bcl-XL protein binds both Bcl-2 homology region 3 and helix 1 of proapoptotic Bax protein to inhibit apoptotic mitochondrial permeabilization. J Biol Chem 289:11873-11896. CrossRef Medline

Duchen MR (2012) Mitochondria, calcium-dependent neuronal death and neurodegenerative disease. Pflugers Arch 464:111-121. CrossRef Medline

Erdö F, Trapp T, Mies G, Hossmann KA (2004) Immunohistochemical analysis of protein expression after middle cerebral artery occlusion in mice. Acta Neuropathol 107:127-136. CrossRef Medline

Formentini L, Pereira MP, Sánchez-Cenizo L, Santacatterina F, Lucas JJ, Navarro C, Martínez-Serrano A, Cuezva JM (2014) In vivo inhibition of the mitochondrial $\mathrm{H}+-\mathrm{ATP}$ synthase in neurons promotes metabolic preconditioning. EMBO J 33:762-778. CrossRef Medline

Galluzzi L, Blomgren K, Kroemer G (2009) Mitochondrial membrane permeabilization in neuronal injury. Nat Rev Neurosci 10:481-494. CrossRef Medline

Gomez-Sanchez JC, Delgado-Esteban M, Rodriguez-Hernandez I, Sobrino T, Perez de la Ossa N, Reverte S, Bolaños JP, Gonzalez-Sarmiento R, Castillo J, Almeida A (2011) The human Tp53 Arg72Pro polymorphism explains different functional prognosis in stroke. J Exp Med 208:429-437. CrossRef Medline

Harley ME, Allan LA, Sanderson HS, Clarke PR (2010) Phosphorylation of Mcl- 1 by CDK1-cyclin $\mathrm{B} 1$ initiates its Cdc20-dependent destruction during mitotic arrest. EMBO J 29:2407-2420. CrossRef Medline

Herrup K (2013) Post-mitotic role of the cell cycle machinery. Curr Opin Cell Biol 25:711-716. CrossRef Medline

Hurd TR, Requejo R, Filipovska A, Brown S, Prime TA, Robinson AJ, Fearnley IM, Murphy MP (2008) Complex I within oxidatively stressed bovine heart mitochondria is glutathionylated on Cys-531 and Cys-704 of the $75-\mathrm{kDa}$ subunit: potential role of CYS residues in decreasing oxidative damage. J Biol Chem 283:24801-24815. CrossRef Medline

Jaquenoud M, van Drogen F, Peter M (2002) Cell cycle-dependent nuclear export of Cdhlp may contribute to the inactivation of $\mathrm{APC} / \mathrm{C}(\mathrm{Cdh} 1)$. EMBO J 21:6515-6526. CrossRef Medline

Javadov S, Hunter JC, Barreto-Torres G, Parodi-Rullan R (2011) Targeting the mitochondrial permeability transition: cardiac ischemia-reperfusion versus carcinogenesis. Cell Physiol Biochem 27:179-190. CrossRef Medline

King TE (1967) Preparation of succinate cytochrome c reductase and the cytochrome b-cl particle, and reconstitution of succinate cytochrome c reductase. Methods Enzymol 10:216-225. CrossRef

Love S (2003) Neuronal expression of cell cycle-related proteins after brain ischaemia in man. Neurosci Lett 353:29-32. CrossRef Medline

Lowry OH, Rosebrough NJ, Lewis-Farr A, Randall RJ (1951) Protein measurement with the Folin phenol reagent. J Biol Chem 193:265-275. Medline

Maestre C, Delgado-Esteban M, Gomez-Sanchez JC, Bolaños JP, Almeida A (2008) Cdk5 phosphorylates Cdh1 and modulates cyclin B1 stability in excitotoxicity. EMBO J 27:2736-2745. CrossRef Medline

Moncada S, Higgs EA, Colombo SL (2012) Fulfilling the metabolic requirements for cell proliferation. Biochem J 446:1-7. CrossRef Medline

Murphy MP (2009) How mitochondria produce reactive oxygen species. Biochem J 417:1-13. CrossRef Medline

Quintana-Cabrera R, Fernandez-Fernandez S, Bobo-Jimenez V, Escobar J, Sastre J, Almeida A, Bolaños JP (2012) gamma-Glutamylcysteine detoxifies reactive oxygen species by acting as glutathione peroxidase- 1 cofactor. Nat Commun 3:718. CrossRef Medline
Ragan CI, Wilson MT, Darley-Usmar VM, Lowe PN (1987) Subfractionation of mitochondria and isolation of the proteins of oxidative phosphorylation. In: Mitochondria: a practical approach (Darley-Usmar VM, Rickwood D, Wilson TM, eds), pp 79-112. London: IRL.

Rashidian J, Iyirhiaro GO, Park DS (2007) Cell cycle machinery and stroke. Biochim Biophys Acta 1772:484-493. CrossRef Medline

Sakurikar N, Eichhorn JM, Chambers TC (2012) Cyclin-dependent kinase-1 (Cdk1)/cyclin B1 dictates cell fate after mitotic arrest via phosphoregulation of antiapoptotic Bcl-2 proteins. J Biol Chem 287:3919339204. CrossRef Medline

Sánchez-Cenizo L, Formentini L, Aldea M, Ortega AD, García-Huerta P, Sánchez-Aragó M, Cuezva JM (2010) Up-regulation of the ATPase inhibitory factor 1 (IF1) of the mitochondrial $\mathrm{H}+$-ATP synthase in human tumors mediates the metabolic shift of cancer cells to a Warburg phenotype. J Biol Chem 285:25308-25313. CrossRef Medline

Sazanov LA (2014) The mechanism of coupling between electron transfer and proton translocation in respiratory complex I. J Bioenerg Biomembr 46:247-253. CrossRef Medline

Schmitt E, Beauchemin M, Bertrand R (2007) Nuclear colocalization and interaction between bcl-xL and cdk1 (cdc2) during G2/M cell-cycle checkpoint. Oncogene 26:5851-5865. CrossRef Medline

Shepherd D, Garland PB (1966) ATP controlled acetoacetate and citrate synthesis by rat liver mitochondria oxidising palmitoyl-carnitine, and the inhibition of citrate synthase by ATP. Biochem Biophys Res Commun 22:89-93. CrossRef Medline

Smith RA, Adlam VJ, Blaikie FH, Manas AR, Porteous CM, James AM, Ross MF, Logan A, Cochemé HM, Trnka J, Prime TA, Abakumova I, Jones BA, Filipovska A, Murphy MP (2008) Mitochondria-targeted antioxidants in the treatment of disease. Ann N Y Acad Sci 1147:105-111. CrossRef Medline

Soper JW, Pedersen PL (1979) Isolation of an oligomycin-sensitive ATPase complex from rat liver mitochondria. Methods Enzymol 55:328-333. CrossRef Medline

Terrano DT, Upreti M, Chambers TC (2010) Cyclin-dependent kinase 1-mediated $\mathrm{Bcl}-\mathrm{xL} / \mathrm{Bcl}-2$ phosphorylation acts as a functional link coupling mitotic arrest and apoptosis. Mol Cell Biol 30:640-656. CrossRef Medline

Upreti M, Galitovskaya EN, Chu R, Tackett AJ, Terrano DT, Granell S, Chambers TC (2008) Identification of the major phosphorylation site in $\mathrm{Bcl}-\mathrm{xL}$ induced by microtubule inhibitors and analysis of its functional significance. J Biol Chem 283:35517-35525. CrossRef Medline

Vander Heiden MG, Chandel NS, Williamson EK, Schumacker PT, Thompson CB (1997) Bcl-xL regulates the membrane potential and volume homeostasis of mitochondria. Cell 91:627-637. CrossRef Medline

Vander Heiden MG, Cantley LC, Thompson CB (2009) Understanding the Warburg effect: the metabolic requirements of cell proliferation. Science 324:1029-1033. CrossRef Medline

Vincent I, Jicha G, Rosado M, Dickson DW (1997) Aberrant expression of mitotic cdc2/cyclin B1 kinase in degenerating neurons of Alzheimer's disease brain. J Neurosci 17:3588-3598. Medline

Wang Y, Qin ZH (2010) Molecular and cellular mechanisms of excitotoxic neuronal death. Apoptosis 15:1382-1402. CrossRef Medline

Wang Z, Fan M, Candas D, Zhang TQ, Qin L, Eldridge A, Wachsmann-Hogiu S, Ahmed KM, Chromy BA, Nantajit D, Duru N, He F, Chen M, Finkel T, Weinstein LS, Li JJ (2014) Cyclin B1/Cdk1 coordinates mitochondrial respiration for cell-cycle G2/M progression. Dev Cell 29:217-232. CrossRef Medline

Wen Y, Yang S, Liu R, Brun-Zinkernagel AM, Koulen P, Simpkins JW (2004) Transient cerebral ischemia induces aberrant neuronal cell cycle re-rentry and Alzheimer's disease-like tauopathy in female rats. J Biol Chem 279: 22684-22692. CrossRef Medline

Wharton DC, Tzagoloff A (1967) Cytochrome oxidase from beef heart mitochondria. Methods Enzymol 10:245-250. CrossRef

White RJ, Reynolds IJ (1996) Mitochondrial depolarization in glutamatestimulated neurons: an early signal specific to excitotoxic exposure. J Neurosci 16:5688-5697. Medline

Yang Y, Mufson EJ, Herrup K (2003) Neuronal cell death is preceded by cell cycle events at all stages of Alzheimer's disease. J Neurosci 23:2557-2563. Medline 